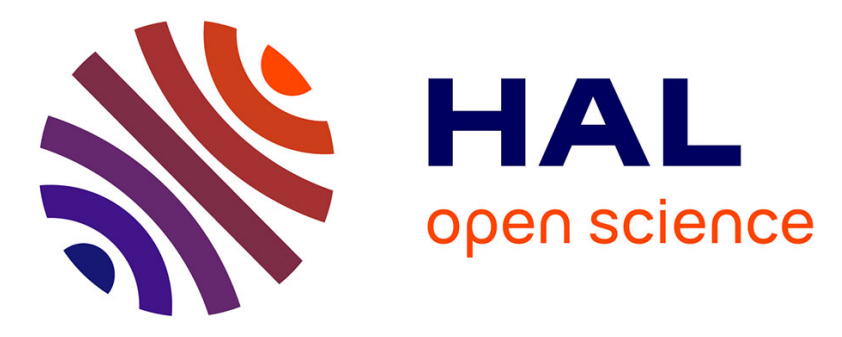

\title{
Radiocesium transfer from hillslopes to the Pacific Ocean after the Fukushima Nuclear Power Plant accident: A review
}

O. Evrard, Jean-Patrick Laceby, Hugo Lepage, Yuichi Onda, Olivier Cerdan, Sophie Ayrault

\section{To cite this version:}

O. Evrard, Jean-Patrick Laceby, Hugo Lepage, Yuichi Onda, Olivier Cerdan, et al.. Radiocesium transfer from hillslopes to the Pacific Ocean after the Fukushima Nuclear Power Plant accident: A review. Journal of Environmental Radioactivity, 2015, 148, pp.92-110. 10.1016/j.jenvrad.2015.06.018 . hal-01401008

\section{HAL Id: hal-01401008 https: / hal-brgm.archives-ouvertes.fr/hal-01401008}

Submitted on 26 May 2020

HAL is a multi-disciplinary open access archive for the deposit and dissemination of scientific research documents, whether they are published or not. The documents may come from teaching and research institutions in France or abroad, or from public or private research centers.
L'archive ouverte pluridisciplinaire HAL, est destinée au dépôt et à la diffusion de documents scientifiques de niveau recherche, publiés ou non, émanant des établissements d'enseignement et de recherche français ou étrangers, des laboratoires publics ou privés. 


\title{
Radiocesium transfer from hillslopes to the Pacific Ocean after the Fukushima Nuclear Power Plant accident: A review
}

\author{
Olivier Evrard ${ }^{\mathrm{a}}$, J. Patrick Laceby ${ }^{\mathrm{a}}$, Hugo Lepage ${ }^{\mathrm{a}}$, Yuichi Onda ${ }^{\mathrm{b}}$, Olivier Cerdan ${ }^{\mathrm{c}}$, Sophie Ayrault ${ }^{\mathrm{a}}$ \\ a'Laboratoire des Sciences du Climat et de l'Environnement (LSCE), Unité Mixte de Recherche 8212 (CEA-CNRS-UVSO/IPSL), \\ Gif-sur-Yvette, France \\ ${ }^{\mathrm{b}}$ Graduate School of Life and Environmental Sciences, Center for Research in Isotopes and Environmental Dynamics (CRIED), \\ University of Tsukuba, Tsukuba, Japan \\ 'Bureau de Recherches Géologiques et Minières, Orléans, France \\ Corresponding Author: O. Evrard (Olivier.Evrard@Isce.ipsl.fr)
}

\section{Highlights}

- The majority of radiocesium is transported in the particulate fraction.

- The contribution of the dissolved fraction is only relevant in base flows.

- Significant transfer of particulate-bound radiocesium occurs during heavy rainfall.

- Radiocesium deposited in floodplains may be remobilized, inducing contamination.

- Transdisciplinary approach is required to quantify radiocesium transfers. 
1 Radiocesium transfer from hillslopes to the Pacific Ocean after the Fukushima

2 Nuclear Power Plant accident: A review

3

4

5

6

Abstract:

The devastating tsunami triggered by the Great East Japan Earthquake on March 11, 2011 inundated the Fukushima Dai-ichi Nuclear Power Plant (FDNPP) resulting in a loss of cooling and a series of explosions releasing the largest quantity of radioactive material into the atmosphere since the Chernobyl nuclear accident. Although $80 \%$ of the radionuclides from this accidental release were transported over the Pacific Ocean, 20\% were deposited over Japanese coastal catchments that are subject to frequent typhoons. Among the radioisotopes released during the FDNPP accident, radiocesium $\left({ }^{134} \mathrm{Cs}\right.$ and $\left.{ }^{137} \mathrm{Cs}\right)$ is considered the most serious current and future health risk for the local population.

The goal of this review is to synthesize research relevant to the transfer of FDNPP derived radiocesium from hillslopes to the Pacific Ocean. After radiocesium fallout deposition on vegetation and soils, the contamination may remain stored in forest canopies, in vegetative litter on the ground, or in the soil. Once radiocesium contacts soil, it is quickly and almost irreversibly bound to fine soil particles. The kinetic energy of raindrops instigates the displacement of soil particles, and their bound radiocesium, which may be mobilized and transported with overland flow. Soil erosion is one of the main processes transferring particle-bound radiocesium from hillslopes through rivers and streams, and ultimately to the Pacific Ocean. Accordingly this review will summarize results regarding the fundamental processes and dynamics that govern radiocesium transfer from hillslopes to the Pacific Ocean published in the literature within the first four years after the FDNPP accident.

The majority of radiocesium is reported to be transported in the particulate fraction and is attached to fine particle size fractions. The contribution of the dissolved fraction to radiocesium migration is only relevant in base flows and is hypothesized to decline over time. Owing to the hydro-meteorological context of the Fukushima region, the most significant transfer of particulate-bound radiocesium occurs during major rainfall and runoff events (e.g. typhoons and spring snowmelt). There may be radiocesium storage within catchments in forests, floodplains and even within hillslopes that may be remobilized and contaminate downstream areas, even areas that did not receive fallout or may have been decontaminated.

Overall this review demonstrates that characterizing the different mechanisms and factors driving radiocesium transfer is important. In particular, the review determined that quantifying the remaining catchment radiocesium inventory allows for a relative comparison of radiocesium transfer research from hillslope to catchment scales. Further, owing to the variety of mechanisms and factors, a transdisciplinary approach is required involving geomorphologists, hydrologists, soil and forestry scientists, and mathematical modellers to comprehensively quantify radiocesium transfers and dynamics. Characterizing radiocesium transfers from hillslopes to the Pacific Ocean is necessary for ongoing decontamination and management interventions with the objective of reducing the gamma radiation exposure to the local population. 


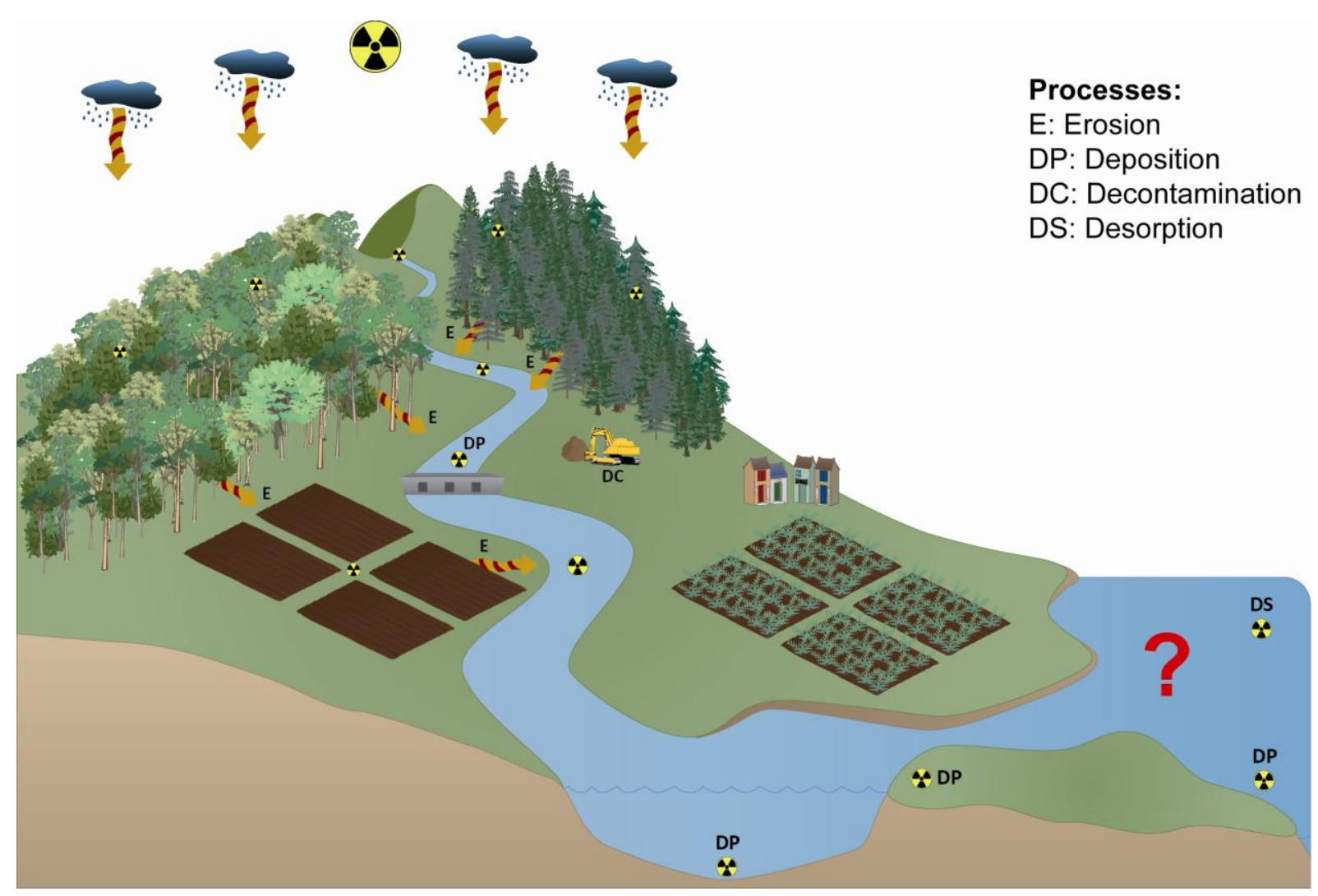




\section{Introduction}

48

49

The Great East Japan Earthquake on March 11, 2011 generated a giant tsunami inundating the Fukushima Dai-ichi Nuclear Power Plant (FDNPP). After the loss of cooling at three FDNPP reactors, a series of explosions occurred resulting in a massive release of radioactive contaminants into the atmosphere. The FDNPP accident resulted in the largest atmospheric release of radioactive material since Chernobyl (Chino et al., 2011; Steinhauser, 2014; Thakur et al., 2013). Although $80 \%$ of the fallout from this atmospheric release was over the ocean, $20 \%$ of fallout was over terrestrial Japan (Groëll et al., 2014; Kawamura et al., 2011; Kobayashi et al., 2013). The terrestrial fallout from the FDNPP accident occurred in a different environmental context than previous major accidents, occurring predominantly in a coastal mountainous region subject to frequent typhoons (Hilton et al., 2008; Shinomiya et al., 2014).

Radiocesium $\left({ }^{134} \mathrm{Cs}\right.$ and $\left.{ }^{137} \mathrm{Cs}\right)$ is considered the most serious risk to the current and long term health of the local population (Kitamura et al., 2014; Saito et al., 2015). The half-life of the two most abundant radiocesium isotopes is 2 y $\left({ }^{134} \mathrm{Cs}\right)$ and 30 y $\left({ }^{137} \mathrm{Cs}\right)$. Therefore, FDNPP derived radiocesium will be an ongoing, long-term source of gamma radiation exposure to the local population. Accordingly, this review will focus on radiocesium transfer from hillslopes to the Pacific Ocean.

Shortly after the FDNPP accident, multiple other radioisotopes were measured in the environment. The wet deposition of hazardous iodine $\left({ }^{131} \mathrm{I}\right.$, half-life of $\left.8 \mathrm{~d}\right)$ was detected along with multiple shortlived radionuclides (Shozugawa et al., 2012; Tagami et al., 2011; Tazoe et al., 2012) (Table 1). However, these short-lived isotopes disappeared quickly and were primarily below detection limits by late April 2011 (Fujiwara et al., 2012). Long-lived isotopes (e.g., ${ }^{239} \mathrm{Pu}\left(\mathrm{T}_{1 / 2}=24100 \mathrm{y}\right),{ }^{240} \mathrm{Pu}\left(\mathrm{T}_{1 / 2}=\right.$ 6560 y)) were also detected (Table 1), although only in trace levels (Evrard et al., 2014b; Schneider et al., 2013; Schwantes et al., 2012). Steinhauser (2014) comprehensively reviewed radionuclides that may have been released by the FDNPP accident which have received less attention. These radionuclides include less volatile elements $\left({ }^{89} \mathrm{Sr},{ }^{90} \mathrm{Sr},{ }^{103} \mathrm{Ru},{ }^{106} \mathrm{Ru}\right)$, pure beta-emitters $\left({ }^{3} \mathrm{H},{ }^{14} \mathrm{C},{ }^{35} \mathrm{~S}\right)$, 
72 gaseous radionuclides $\left({ }^{85} \mathrm{Kr},{ }^{133} \mathrm{Xe},{ }^{135} \mathrm{Xe}\right)$ or radionuclides with very long half-lives $\left(\mathrm{e} . \mathrm{g} .,{ }^{36} \mathrm{Cl},{ }^{99} \mathrm{Tc},{ }^{129} \mathrm{l}\right.$, $\left.73{ }^{236} \mathrm{U}\right)($ Table 1).

Table 1. Radionuclides detected in environmental samples after the FDNPP accident

\begin{tabular}{|c|c|c|c|}
\hline Radionuclide & $\begin{array}{l}\text { Half-life } \\
\text { (d) }\end{array}$ & Half-life (y) & Reference \\
\hline${ }^{129} \mathrm{Te}$ & 0.05 & -- & Tazoe et al. (2012) \\
\hline 132 & 0.10 & -- & Shozugawa et al. (2012) \\
\hline${ }^{135} \mathrm{Xe}$ & 0.38 & -- & Steinhauser (2014) \\
\hline${ }^{91} \mathrm{Sr}$ & 0.40 & -- & Shozugawa et al. (2012) \\
\hline${ }^{140} \mathrm{La}$ & 1.70 & -- & Shozugawa et al. (2012); Tagami et al. (2011) \\
\hline${ }^{133 m} \mathrm{Xe}$ & 2.20 & -- & Steinhauser (2014) \\
\hline${ }^{239} \mathrm{~Np}$ & 2.35 & -- & Shozugawa et al. (2012) \\
\hline${ }^{132} \mathrm{Te}$ & 3.30 & -- & Shozugawa et al. (2012)) \\
\hline${ }^{133} \mathrm{Xe}$ & 5.25 & -- & Steinhauser (2014) \\
\hline${ }_{131}$ & 8.00 & -- & Shozugawa et al. (2012); Tagami et al. (2011); Tazoe et al. (2012) \\
\hline${ }^{131 \mathrm{~m}} \mathrm{Xe}$ & 11.90 & -- & Steinhauser (2014) \\
\hline${ }^{140} \mathrm{Ba}$ & 12.80 & -- & Shozugawa et al. (2012) \\
\hline${ }^{136} \mathrm{Cs}$ & 13.20 & -- & Tagami et al. (2011) \\
\hline${ }^{129 m} \mathrm{Te}$ & 33.60 & -- & Tagami et al. (2011); Tazoe et al. (2012) \\
\hline${ }^{95} \mathrm{Nb}$ & 35.00 & -- & Shozugawa et al. (2012); Tagami et al. (2011) \\
\hline${ }^{103} \mathrm{Ru}$ & 39.40 & -- & Steinhauser (2014) \\
\hline${ }^{59} \mathrm{Fe}$ & 44.60 & -- & Shozugawa et al. (2012) \\
\hline${ }^{89} \mathrm{Sr}$ & 50.53 & -- & Steinhauser (2014) \\
\hline${ }^{91} Y$ & 58.50 & -- & Shozugawa et al. (2012) \\
\hline${ }^{95} \mathrm{Zr}$ & 64.00 & -- & Shozugawa et al. (2012) \\
\hline${ }^{35} \mathrm{~S}$ & 87.37 & -- & Steinhauser (2014) \\
\hline${ }^{110 m} \mathrm{Ag}$ & 252.00 & -- & Shozugawa et al. (2012); Tagami et al. (2011); Tazoe et al. (2012) \\
\hline${ }^{134} \mathrm{Cs}$ & -- & 2.06 & Tagami et al. (2011); Tazoe et al. (2012) \\
\hline${ }^{85} \mathrm{Kr}$ & -- & 10.75 & Steinhauser (2014) \\
\hline${ }^{3} \mathrm{H}$ & -- & 12.32 & Kakiuchi et al. (2012); Steinhauser (2014) \\
\hline${ }^{241} \mathrm{Pu}$ & -- & 14.33 & Steinhauser (2014) \\
\hline${ }^{137} \mathrm{Cs}$ & -- & 30.20 & Shozugawa et al. (2012); Tagami et al. (2011); Tazoe et al. (2012) \\
\hline${ }^{238} \mathrm{Pu}$ & -- & 87.70 & Steinhauser (2014) \\
\hline${ }^{241} \mathrm{Am}$ & -- & 432.60 & Steinhauser (2014) \\
\hline${ }^{14} \mathrm{C}$ & -- & 5730.00 & Steinhauser (2014) \\
\hline${ }^{240} \mathrm{Pu}$ & -- & 6561.00 & Steinhauser (2014) \\
\hline${ }^{239} \mathrm{Pu}$ & -- & 24110.00 & Shozugawa et al. (2012); Steinhauser (2014) \\
\hline${ }^{99} \mathrm{Tc}$ & -- & $2.10 \mathrm{E}+05$ & Steinhauser (2014) \\
\hline${ }^{36} \mathrm{Cl}$ & -- & $3.00 E+05$ & Steinhauser (2014) \\
\hline${ }^{129} \mathrm{I}$ & -- & $1.57 \mathrm{E}+07$ & Steinhauser (2014) \\
\hline${ }^{236} \mathrm{U}$ & -- & $2.34 \mathrm{E}+07$ & Steinhauser (2014) \\
\hline${ }^{235} \mathrm{U}$ & -- & $7.04 E+08$ & Steinhauser (2014) \\
\hline${ }^{238} \mathrm{U}$ & -- & $4.47 E+09$ & Steinhauser (2014) \\
\hline
\end{tabular}


Researching less abundant radionuclides may provide useful and complementary information on the events that occurred at FDNPP (Achim et al., 2014; Le Petit et al., 2014). However, owing to the potential gamma radiation exposure, there has been an increasing focus in the literature on the transfer, fate, dynamics and consequences of radiocesium in the fallout impacted region. Before the accident, there were on average six publications a year with Fukushima in the title (Fig. 1). After the accident (from 2011 to 2014), this average increased over 50 fold to approximately 350 publications a year. Of these publications, the percent of published research including radiocesium as a topic increased from 8\% in 2011 to 32\% in 2014 indicating that radiocesium, in the fallout impacted region, is of increasing significance to the scientific community.
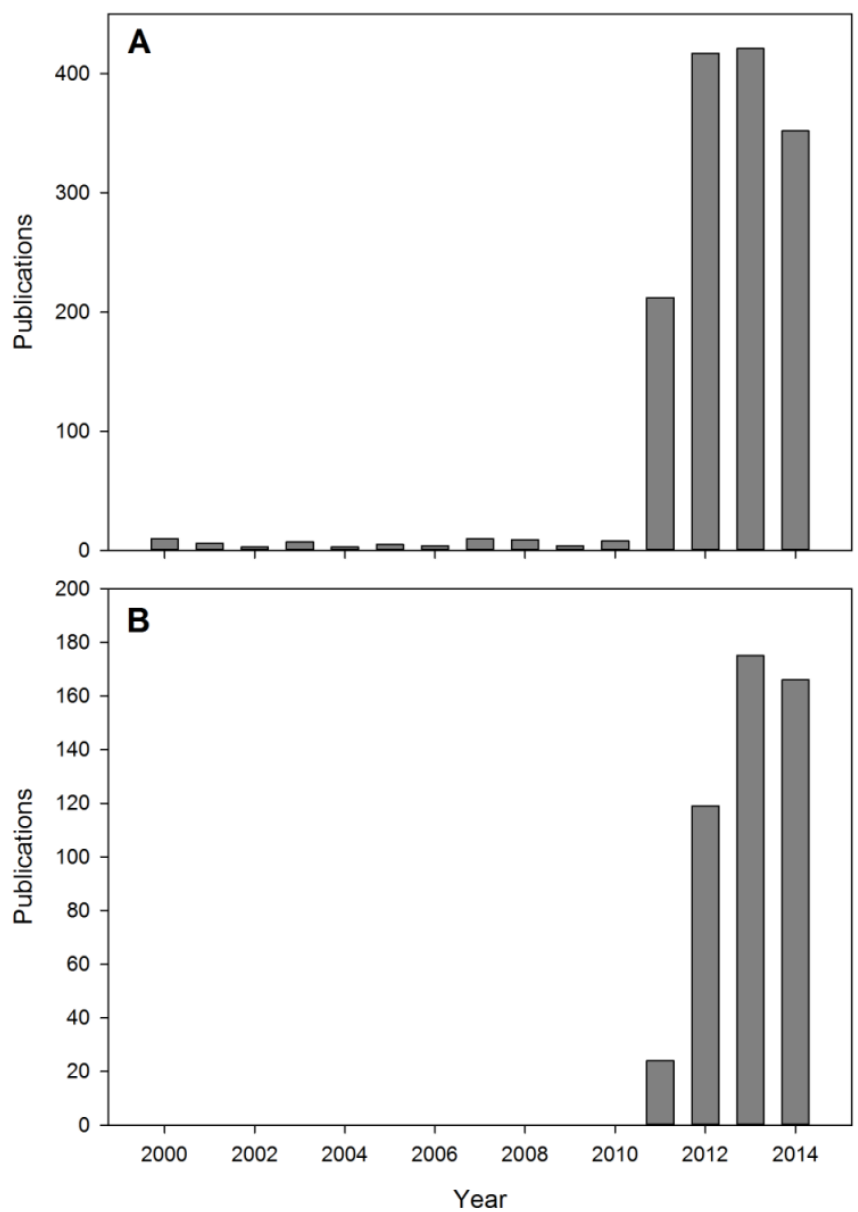

Figure 1. Annual publications with Fukushima in the title (A - top), and Fukushima in the title with Cesium/Caesium included the topic (B - bottom) from a Web of Science search conducted early in January 2015. 
Initially radiocesium was deposited on terrestrial vegetation and soils. Depending on local conditions, the contamination may remain stored in the forest canopy, in the vegetative litter on the ground or in the soil. Once radiocesium contacts soil, it is quickly and almost irreversibly bound to fine soil particles (He and Walling, 1996; Sawhiney, 1972; Tamura, 1964). During rainfall, the kinetic energy of raindrops instigates the displacement of soil particles and their bound radiocesium, which are mobilized and transported with rainfall runoff (Renard et al., 1991; Torri et al., 1987)(Fig. 2). Soil erosion is considered to be the main process transferring particle-bound radiocesium from hillslopes through rivers and streams, and ultimately to the Pacific Ocean (Yoshida and Kanda, 2012)(Fig. 2).

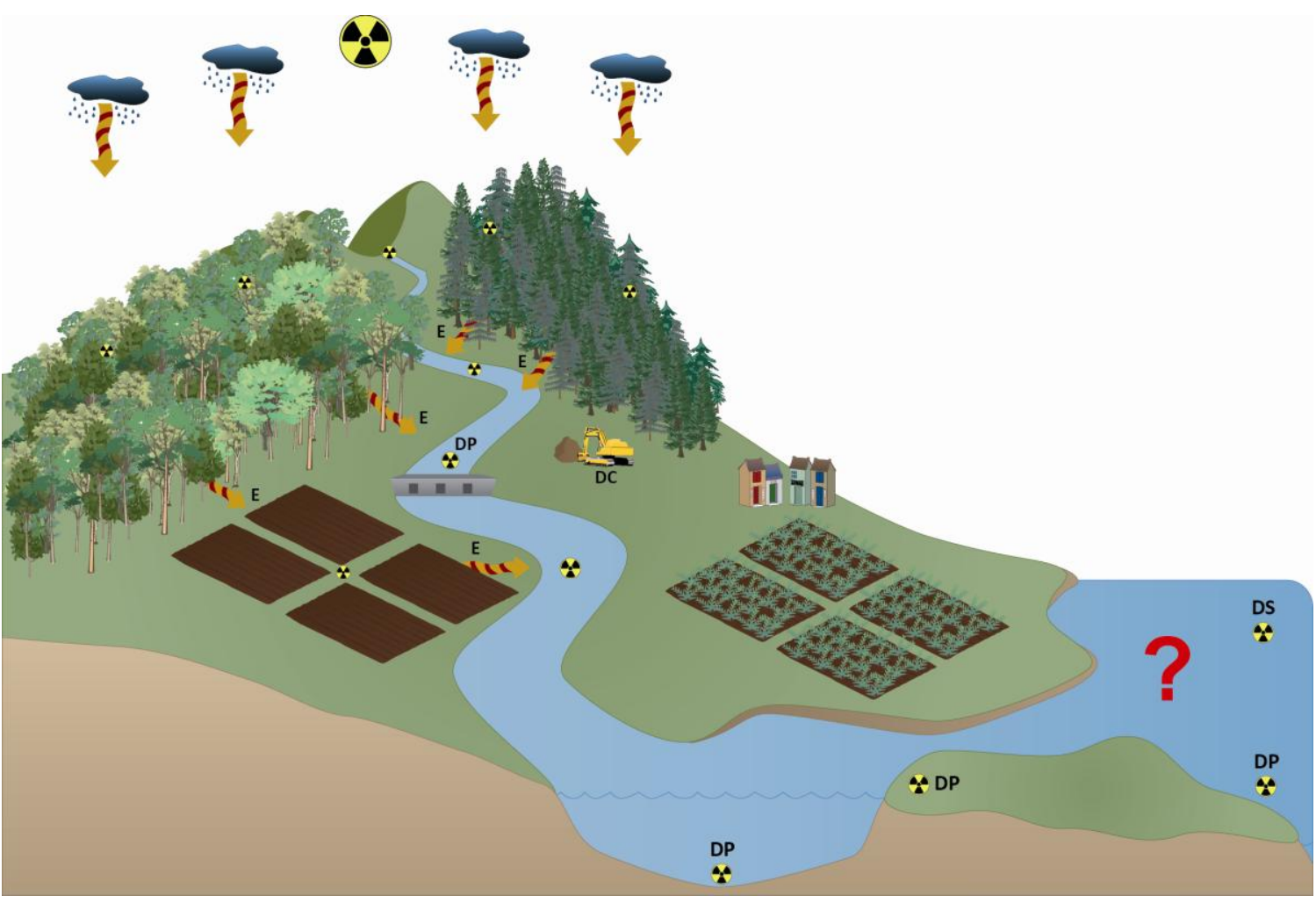

Figure 2. Potential pathways for radiocesium transfer from hillslopes to the Pacific Ocean following the FDNPP accident denoting major processes such as erosion (E), deposition (DP), decontamination (DC) and desorption (DS) (Images courtesy of the Integration and Application Network, University of Maryland Center for Environmental Science (ian.umces.edu/symbols/)).

The transfer of particulate-bound radiocesium may be substantial during typhoons typically occurring between June and October in Japan. Importantly, the fine particles, to which radiocesium is preferentially bound to, are the particles that are preferentially eroded and likely to be transported 
the farthest during erosive rainfall events (Govers, 1985; Malam Issa et al., 2006; Motha et al., 2002). Fundamentally, soil erosion and riverine transport processes are the primary factors governing the long-distance transfer of radiocesium from hillslopes to the Pacific Ocean (Kitamura et al., 2015; Saito and Onda, 2015; Yamada et al., 2015).

The goal of this review is to synthesize research relevant to the transfer of FDNPP derived radiocesium outlined in the previous paragraph. The main objective is to comprehensively review literature investigating the fundamental processes and dynamics governing radiocesium transfer from hillslopes to the Pacific Ocean published within $4 \mathrm{y}$ of the FDNPP accident. This review will conclude with recommendations for future research and for the design and implementation of effective countermeasures.

\section{Fallout radiocesium deposition}

Although radionuclides from the FDNPP accident were detected worldwide (Evrard et al., 2012; Long et al., 2012; Masson et al., 2011; Wetherbee et al., 2012), the majority of terrestrial deposition occurred in the Fukushima Prefecture. The main radiocesium plume is located northwest of the FDNPP, with a secondary plume in the Abukuma River Valley southwest from Fukushima City past Koriyama (Fig. 3). There are multiple approaches to quantify catchment radiocesium inventories including both airborne and soil sampling surveys (Gonze et al., 2014; Saito et al., 2015; Yoshida and Takahashi, 2012). As this review examines the transfer of radiocesium from hillslopes to the Pacific Ocean, we used soil sampling surveys to quantify the total, mean, and standard deviation of radiocesium $\left({ }^{134} \mathrm{Cs}+{ }^{137} \mathrm{Cs}\right)$ fallout in 14 coastal catchments of the Fukushima region (Fig. 3, Table 2). This quantification of catchment inventories is based on the spatial interpretation conducted by Chartin et al. (2013) of 2200 soil samples collected by the Japanese Ministry of Education, Culture, Sports, Science and Technology (MEXT, 2012) between June and July 2011. 


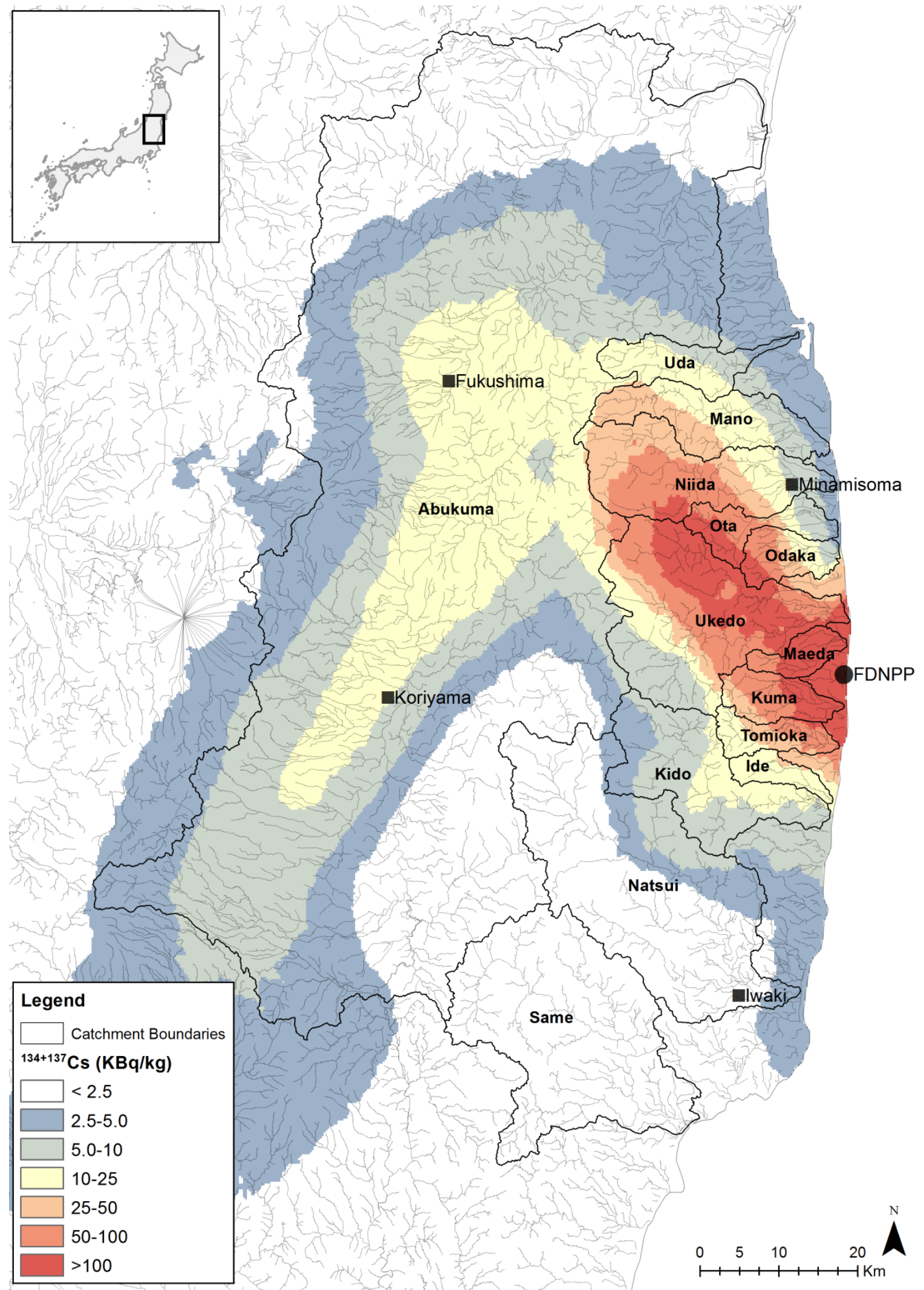

Figure 3. Labelled coastal catchments impacted by the fallout from the FDNPP accident, major rivers (grey lines), the location of the FDNPP (black circle) and major cities (black squares), and the spatial distribution of radiocesium fallout $\left({ }^{134} \mathrm{Cs}+{ }^{137} \mathrm{Cs}\right)$ in $\mathrm{kBq} / \mathrm{kg}$ provided by Chartin et al. (2013) who spatially interpreted (ordinary kriging) the radiocesium distribution of 2200 soil samples taken by the Japanese Ministry of Education, Culture, Sports, Science and Technology (MEXT) between June and July 2011 decay corrected to June 14, 2011. 
Table 2. Radiocesium $\left({ }^{134} \mathrm{Cs}+{ }^{137} \mathrm{Cs}\right)$ inventory received by the major coastal catchments in Fukushima region (Coastal catchment data derived from the Japanese Ministry of Land, Infrastructure, Transport and Tourism (http://nlftp.mlit.go.jp/ksj-e/index.html)) and the radiocesium inventories were calculated with data from Chartin et al. (2013) spatially interpreted radiocesium inventory calculations from Fig. 3 converted to total Cs from Bg/kg.

\begin{tabular}{lcccc}
\hline Catchment & $\begin{array}{c}\text { Area } \\
\left(\mathbf{k m}^{2}\right)\end{array}$ & $\begin{array}{c}\text { Total } \\
\text { Inventory } \\
(\mathbf{T B q})\end{array}$ & $\begin{array}{c}\text { \% of } \\
\text { Total } \\
\text { Inventory }\end{array}$ & $\begin{array}{c}\text { Deposition } \\
\text { Density } \\
\left(\mathbf{T B q} \mathbf{~ k m}^{-2} \mathbf{)}\right.\end{array}$ \\
\hline Abukuma & 5338 & 734.9 & $30 \%$ & 0.14 \\
Ukedo & 423 & 643.9 & $26 \%$ & 1.52 \\
Niida & 265 & 283.4 & $12 \%$ & 1.07 \\
Kuma & 75 & 161.4 & $7 \%$ & 2.14 \\
Maeda & 45 & 149.9 & $6 \%$ & 3.32 \\
Ota & 77 & 111.0 & $5 \%$ & 1.44 \\
Odaka & 68 & 81.4 & $3 \%$ & 1.20 \\
Mano & 171 & 78.1 & $3 \%$ & 0.46 \\
Tomioka & 62 & 58.6 & $2 \%$ & 0.95 \\
Kido & 263 & 48.6 & $2 \%$ & 0.18 \\
Natsui & 696 & 36.3 & $1 \%$ & 0.05 \\
Uda & 101 & 27.6 & $1 \%$ & 0.27 \\
Same & 601 & 19.2 & $1 \%$ & 0.03 \\
Ide & 40 & 16.2 & $1 \%$ & 0.14 \\
\hline
\end{tabular}

127 The Abukuma catchment received the most radiocesium fallout, followed by the Ukedo and Niida catchments (Table 2). Radiocesium inventories for the 14 coastal catchments ranged between 734.9 $\mathrm{TBq}$ in the Abukuma to $16.2 \mathrm{TBq}$ in the Ide catchment. The Abukuma catchment received approximately $30 \%$ of the fallout received by these 14 catchments, followed by $26 \%$ for the Ukedo and $12 \%$ for the Niida. Although the Abukuma catchment received the highest amount of fallout, the

132 radiocesium was distributed over a broad spatial area and the mean deposition density in the 133 Abukuma catchment was $0.14 \mathrm{TBq} \mathrm{km}^{2}$. Comparatively, the smaller coastal catchments had the 134 highest mean radiocesium inventories, particularly the Meada (3.32 TBq km$\left.{ }^{-2}\right)$, Kuma $\left(2.14 \mathrm{TBq} \mathrm{km}^{-2}\right)$, 135 Ukedo (1.52 TBq km$\left.{ }^{-2}\right)$, Ota $\left(1.44 \mathrm{TBq} \mathrm{km}{ }^{-2}\right)$, Odaka $\left(1.20 \mathrm{TBq} \mathrm{km}{ }^{-2}\right)$, and Niida $(1.07 \mathrm{TBq} \mathrm{km}$ ) catchments.

137 Although quantifying catchment inventories with airborne and soil based sampling techniques or 138 different spatial interpretation approaches may yield different results (Gonze et al., 2014), what is 
important to the research and management community is the spatial distribution of radiocesium. In particular, characterizing the deposition of radiocesium, especially the different catchments and landscapes receiving the fallout (e.g different forest types), is important for understanding the sources and spatial distribution of radiocesium available for transfer from hillslopes to the Pacific Ocean.

\subsection{Forest deposition}

Significant radiocesium deposition occurred on forested landscapes. Approximately $66 \%$ of high levels of radioactive fallout $\left(>1000 \mathrm{kBq} \cdot \mathrm{m}^{-2}\right.$ ) took place over a mixture of deciduous and coniferous forests (Hashimoto et al., 2012). As the accident occurred during late winter and deciduous trees had no leaves, the fallout more directly contaminated the ground surface (soil and litter). In coniferous forests, with their needles intact, the fallout radiocesium was partly intercepted by the forest canopy. In particular, Kato et al. (2012a) estimated that between $62 \%$ and $65 \%$ of ${ }^{137}$ Cs was intercepted by the canopies of cypress and cedar forests, respectively. When examining both deciduous and coniferous forests, Koizumi et al. (2013) modelled that $\sim 10 \%$ of the ${ }^{137}$ Cs deposited on forests within the exclusion zone was trapped by biomass.

The majority of research has focused on Japanese Cedar (Cryptomeria japonica) followed by the mixed forests and coniferous forest with broad leaf forests receiving the least attention (Fig. 4). The research, in particular research examining Japanese Cedar, has been widespread throughout the fallout impacted region and across northern Japan (Fig. 4). As the forested areas within $20 \mathrm{~km}$ of the FDNPP (Koizumi et al., 2013) are approximately 50\% broadleaf and 50\% needle-leaf forest, it may be advantageous for future research to examine radiocesium dynamics equally in broadleaf, coniferous and mixed forests within the highly contaminated coastal catchments.

After canopy interception, the radiocesium transfer pathway from the canopy to the soil is complex (Fig. 5). Radiocesium may transfer through leaf surface tissues or remain on the foliar surface. A portion of foliar radiocesium (17 - 59\%) was measured inside leaves within a year, whereas the 
(Koizumi et al., 2013; Nishikiori et al., 2015; Tanaka et al., 2013a). Results were similar for deciduous (46\% removed after washing) and coniferous canopies (41\%) (Koizumi et al., 2013) indicative of a potential long-term radiocesium source where canopies intercepted significant quantities of radiocesium.

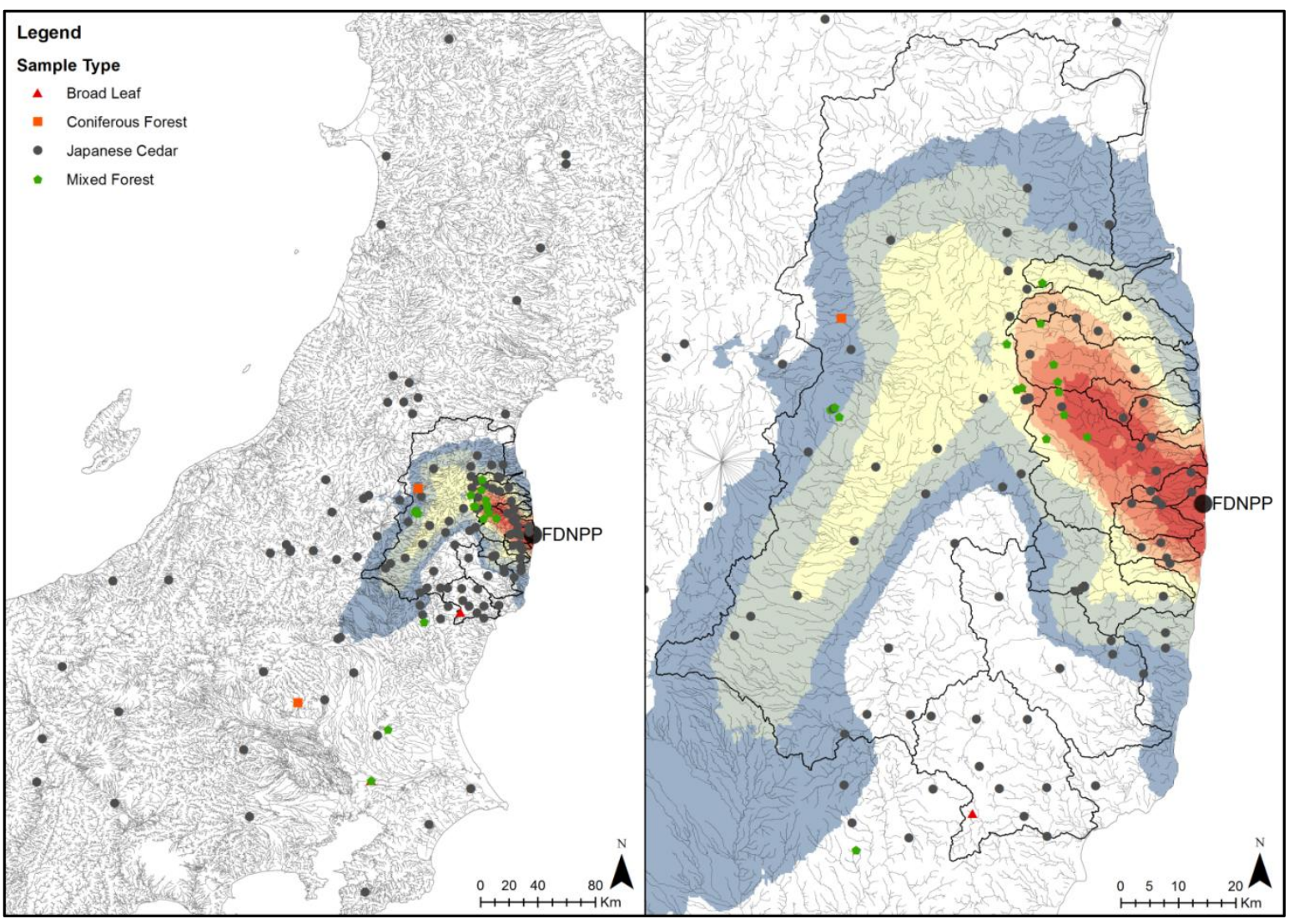

Figure 4. Localisation of samples examining radiocesium processes and dynamics in forests after the FDNPP Accident. Multiple samples may have been obtained at one location.

During the first year after the accident, foliar contamination was mainly due to the radiocesium deposition. After the initial deposition, radiocesium may translocate between old and new vegetative tissues (Nishikiori et al., 2015; Yoshihara et al., 2014b). In most studies, a decrease of contamination

172 was observed between old and young needles in coniferous forests (Akama et al., 2013; Kanasashi et 173 al., 2015; Nishikiori et al., 2015; Yoshihara et al., 2013). In contrast, Yoshihara et al. (2014b) reported 174 that new foliar growth in 2013 contained more radiocesium than 2011 samples in coniferous forests. 


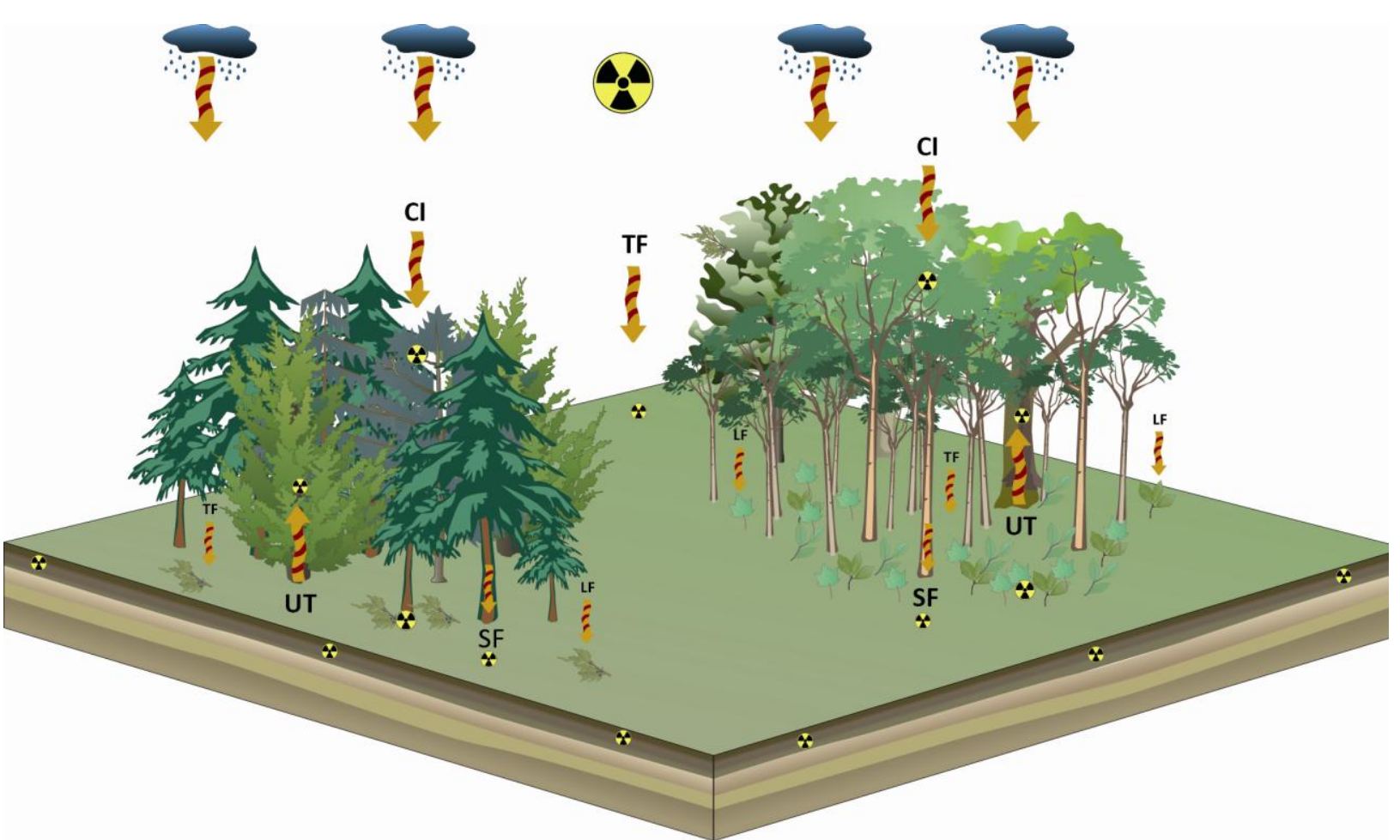

Figure 5. An illustration of the major radiocesium transfer pathways in forested (coniferous - to the left - and deciduous - to the right) landscapes. The major transfer pathways to the soil include throughfall (TF), canopy interception (Cl), litter fall (LF) and stem flow (SF). There is also potential for the flora to uptake (UT) radiocesium (Images courtesy of the Integration and Application Network, University of Maryland Center for Environmental Science (ian.umces.edu/symbols/)).

For deciduous forests, research into foliar contamination is inconclusive. Tanaka et al. (2013a) did not observe any contamination in new leaves. Nishikiori et al. (2015) reported that although leaves were absent during the accident, contamination was detected in leaves sampled in 2012. Yoshihara et al. (2014a) found no significant variation in leaves sampled in 2011 and 2012. Additional factors may explain tree contamination such as root uptake, stem transfer, or surficial contamination due to wind-eroded particle deposition. cumulative long-term radiocesium export from forest environments. During rainfall events, radiocesium is more likely to be transferred by throughfall than by stemflow, although both 
pathways increase ground contamination (Kato et al., 2012a; Loffredo et al., 2014). The effective half-life of radiocesium in trees was calculated to be $620 \mathrm{~d}$ for cypress and $890 \mathrm{~d}$ for cedar canopies (Kato et al., 2012a). Accordingly, there will likely be a medium to long-term canopy to ground stemflow and throughfall transfer of radiocesium (Kato et al., 2012a).

Litterfall is a significant radiocesium transfer pathway. In fact, litterfall was reported to transfer as much radiocesium as throughfall (Teramage et al., 2014a). Further, Hasegawa et al. (2013) reported that radiocesium concentrations in litter were greater than those measured in the soil. In the future, litterfall will likely become the dominant pathway for radiocesium transfer from the canopy to the forest floor as hydrological pathways transfer less radiocesium with time owing to decreased availability (Teramage et al., 2014a). In addition, Kuroda et al. (2013) found that the tree bark was highly contaminated. More than $94 \%$ of the stem contamination was located in the bark, indicative of another potential long-term source of radiocesium derived either from surficial contamination or through contaminated phloem sap.

The quantity of radiocesium in the litter depends on multiple factors such as tree species, location of the forest in the radioactive pollution plume, or sampling date. Matsunaga et al. (2013) did not observe specific migration of radiocesium from litter to soil after the first rainfall event (July-August 2011). Nakanishi et al. (2014) reported a decrease of ${ }^{137}$ Cs contamination in litter from $67 \%$ to $13 \%$ during the first year, whereas contamination in soil increased from $26 \%$ to $80 \%$. Takahashi et al. (2015) found that the proportion of radiocesium in leaf litter, relative to soil, decreased from $~ 90 \%$ in 2011 to $18-14 \%$ in 2012. Fujii et al. (2014) also noted a significant decrease in the percentage of radiocesium in the leaf litter, decreasing from between $44-65 \%$ in 2011 to $14-27 \%$ in 2012 . The transfer of radiocesium from litter to soil is controlled by rainfall and litter decomposition. Research estimates that around $30 \%-40 \%$ of litter in Japanese forests is decomposed annually (Hashimoto et al., 2012; Matsunaga et al., 2013). 
In the Fukushima region, forests are a radiocesium reservoir, retaining significant quantities of

212 radiocesium within both the canopy and the leaf litter (Hashimoto et al., 2012; Koarashi et al.,

213 2012a). Although forested landscapes are not considered to be significant erosion sources

214 (Yoshimura et al., 2015a), there is an abundance of radiocesium within these systems, often stored in organic matter, that may be transferred downstream during significant rainfall events. Accordingly, forest landscapes may potentially become perennial sources of radiocesium in the Fukushima region. Understanding both intra- and inter- forest radiocesium transfers will be fundamental to understanding radiocesium transfer and export by soil erosion and wash-off. Incorporating differences between deciduous and coniferous forests and their different rates of radiocesium transfer is important for modelling hillslope exports and cumulative radiocesium transfers from

221 hillslopes to the Pacific Ocean.

\subsection{Soil deposition}

223 Upon contact with the soil, it is well known that radiocesium is strongly and rapidly fixated to fine soil 224 particles (He and Walling, 1996; Sawhiney, 1972). Cesium is an alkali metal and accordingly it possesses similar chemical properties to potassium and may substitute for potassium in interactions with clay minerals resulting in an almost irreversible fixation to fine soil particles (Kitamura et al., 2015).

Following the Fukushima accident, researchers have extensively examined radiocesium fixation to 229 fine particles (Akai et al., 2013; Saito et al., 2014; Tanaka et al., 2013c). These examinations were undertaken primarily because of the high organic matter and clay content of soils in the Fukushima region that may influence the depth migration of radiocesium in the soil profile. In particular, there has been a research focus on the physical and chemical foundation of the fixation of radiocesium to fine particles and the depth migration of radiocesium in the soil profile. Characterizing the fixation potential of radiocesium to fine soil particles is fundamental to understanding potential radiocesium 
migration pathways including the mobilization and transport of radiocesium, and ultimately its transfer through rivers and streams to the Pacific Ocean.

Compared to the forest radiocesium research, there has not been a similar regional coverage of soil sampling across northern Japan (Fig. 6). The majority of samples examining soil transfer processes including depth migration or fixation potential were taken within the 14 coastal catchments with a well distributed coverage across the fallout impacted region. The focus of soil sampling is mainly on paddy fields with a substantial number samples having unclassified land uses. The inclusion of land use details would be beneficial to future research examining radiocesium transfer processes.

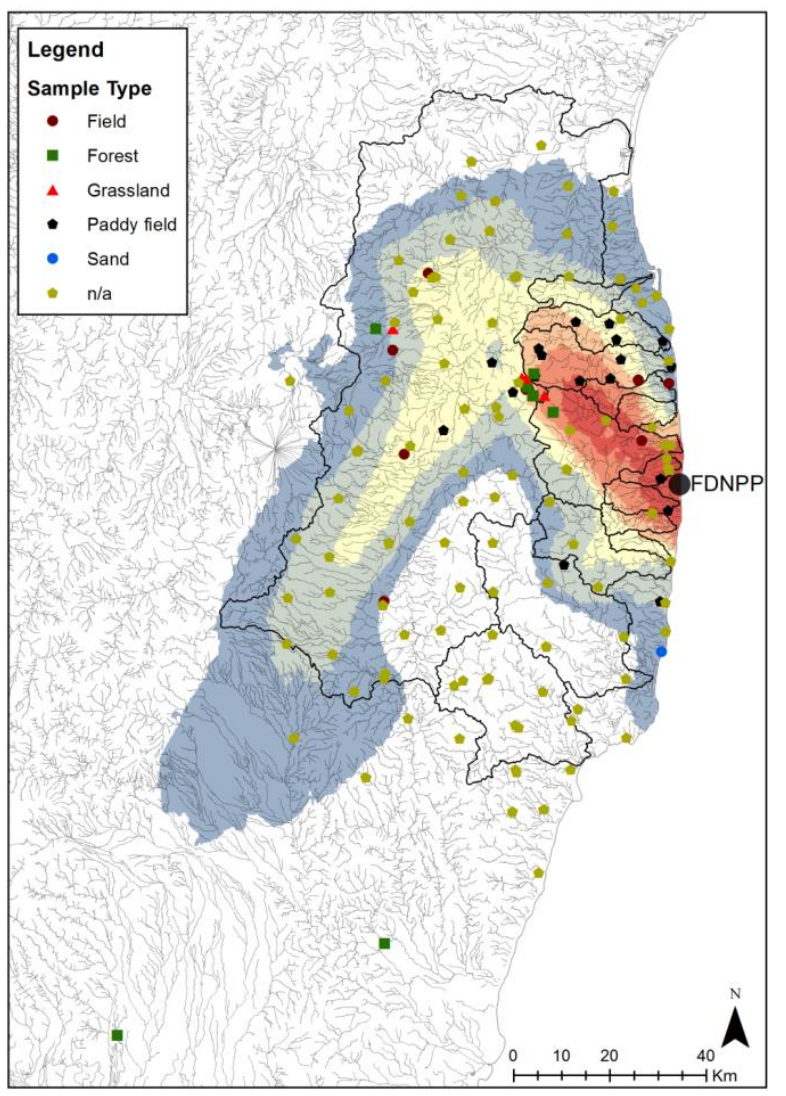

Figure 6. Location of soil sampling locations where research examined radiocesium dynamics or process such as depth migration in the soil profile or fixation to the mineral or soil fractions. More than one sample may occur at any given location.

Immediately after the FDNPP accident, Tanaka et al. (2013c) reported that the radiocesium was water soluble, though once radiocesium adsorbed on to soil and rock particles it quickly became essentially insoluble. The increase in insolubility was also reported by Shiozawa (2013) who indicated 
that the strong fixation of radiocesium to clay particles during the initial $2-3$ months after the

247 accident reduced the migration of radiocesium in the depth profile. The strong fixation to clay

248 particles was again reported by Saito et al. (2014) and Kikawada et al. (2014) who indicated that virtually no radiocesium was extractable from soil samples with simple water solutions.

Using X-ray diffraction, Saito et al. (2014) reported that micaceous minerals (e.g. muscovite, biotite, and illite) were responsible for the strong radiocesium soil fixation. Conversely, Kozai et al. (2012) utilized desorption experiments to determine that radiocesium was almost irreversibly fixated to the non-micaceous soil minerals. Niimura et al. (2015) reported that radiocesium fixation is due to a physical adherence to the rough surfaces of the soil mineral particles. These different approaches to understanding radiocesium fixation indicate that the physical processes behind this strong fixation are difficult to characterize and are dependent upon multiple parameters such as experiment characteristics, mineral contents, and/or the physical-chemical characteristics of both the fallout radiocesium itself and the soil medium.

The extractability of radiocesium was found to be higher in forest soils with higher contents of clay and silt particles, and a higher cation exchange capacity (Koarashi et al., 2012b). Using extraction processes with $\mathrm{K}_{2} \mathrm{SO}_{4}$, Koarashi et al. (2012b) reported that only 2.1 to $12.8 \%$ of Fukushimaoriginated radiocesium found in the surface mineral soils were retained as easily exchangeable ions by abiotic components in forest sites. Potential uptake and retention of ${ }^{137} \mathrm{Cs}$ by microorganisms in the forest surface soils $(0-3 \mathrm{~cm})$ were found to be minor and less important than ion-exchange adsorption on non-specific sites provided by abiotic components (Koarashi et al., 2012b). In the longterm, microorganisms in forest soils may contribute to the mobilization of radiocesium by decomposition of the soil organic matter (e.g. leaf litter) (Koarashi et al., 2012b).

Research prior to the FDNPP accident clearly indicates that in undisturbed soils an exponential decline of radiocesium in the soil profile is expected along with a very slow radiocesium depth migration in the soil profile (He and Walling, 1997). In fact, the radiocesium peak from nuclear 
272 (Jagercikova et al., 2015).

273 Owing to the strong and irreversible bond to fine soil particles, the majority of FDNPP derived 274 radiocesium currently remains stored within the top $5 \mathrm{~cm}$ of the soil profile in undisturbed soils 275 (Lepage et al., 2014b; Matsuda et al., 2015; Matsunaga et al., 2013; Mishra et al., 2015; Takahashi et 276 al., 2015). Anthropogenic activities increase the depth of migration of radiocesium in the soil profile 277 (Lepage et al., In Press; Matsunaga et al., 2013). Erosion and subsequent deposition processes may 278 also result in the increase of radiocesium with depth in the soil profile similarly to carbon and other 279 minerals in depositional landscapes (Van Oost et al., 2012). Lepage et al. (In Press) demonstrated that $90 \%$ of radiocesium remained in the upper $5 \mathrm{~cm}$ of the soil profile after deposition in non-cultivated soils, whereas within cultivated soils the contamination was homogeneous throughout the tilled soil layer (generally down to $15-30 \mathrm{~cm}$ ). Endo et al. (2013) demonstrated that radiocesium concentrations were not dependent on depth in rice paddy field soils, whereas they declined exponentially in an uncultivated soil. Sakai et al. (2014) and Tanaka et al. (2013b) both indicated that radiocesium from the FDNPP accident was measureable at $15 \mathrm{~cm}$ depth in rice paddy fields. Mishra et al. (2015) reported that the vertical migration down the soil profile was slower in forest soils than in grassland soils. In a study of 85 soil sampling sites, Matsuda et al. (2015) found that the depth 288 penetration of radiocesium was higher than the standard range $\left(0.2-1.0 \mathrm{~kg} \mathrm{~m}^{-2} \mathrm{y}^{-1}\right)$ depicted by He 289 and Walling (1997).

Multiple researchers have postulated different hypotheses for the observed depth migration of radiocesium in the soil profile. Fujiwara et al. (2012) reported that the elevated rates of radiocesium migration down the soil profile are potentially indicative of the mobile form of radiocesium 293 immediately after the accident. Kato et al. (2012b) also observed increased downwards migration of 294 radiocesium immediately and attributed this phenomenon to high clay content that increased the 295 aggregate stability of topsoil resulting in increased water and radiocesium infiltration deeper into the 
soil profile. Conversely, Satou et al. (2015) investigated the vertical migration in coarse-grained beach material impacted by the tsunami. The authors demonstrated that the majority of radiocesium was located at $\sim 3-6 \mathrm{~cm}$ depth. This migration is likely due to coarser grained material indicative of a potential particle size impact on the depth migration of radiocesium.

The depth migration of radiocesium also depends on soil properties. Koarashi et al. (2012a) demonstrated that clay and organic matter content are key factors controlling radiocesium depth migration. Organic matter inhibits the fixation of radiocesium on the soil mineral fraction by limiting its access to adsorption sites on clay minerals through direct competition for potential adsorption sites. As organic matter may limit the adsorption of radiocesium, it may also influence the rate of radiocesium depth migration. The impact of organic matter is particularly notable in forests. The high organic content of forest soils increases the potential for radiocesium depth migration (Koarashi et al., 2012a). Nakanishi et al. (2014) demonstrated that $0.1 \%$ of the radiocesium deposited on the forest floor indeed migrated below $10 \mathrm{~cm}$ depth in $1 \mathrm{y}$.

The timing and extent of rainfall may also drive the migration of radiocesium deeper within the soil profile. The rainfall that occurred immediately after the accident fallout may have been a factor in the radiocesium depth migration in forest soils (Teramage et al., 2014b) along with rainfall volume in general (Fujii et al., 2014). Further, rainfall was listed as a potential factor for the depth migration in the beach sand samples (Satou et al., 2015). The average rainfall in the Fukushima region is more than 2 times greater than Chernobyl and the rainfall erosivity is almost 3 times greater (Laceby et al., submitted). Both the elevated rainfall intensity and volume may have resulted in greater depth penetration of radiocesium in the Fukushima region compared to that of Chernobyl.

Migration of radiocesium was also correlated with low bulk densities as highly porous structures may facilitate water and potentially dissolved radiocesium infiltration deeper down the soil profile (Koarashi et al., 2012a; Takahashi et al., 2015). The radiocesium interception potential (RIP) is often used to quantify this process. The RIP describes the capacity of the mineral content of soils to adsorb 
radiocesium (Wauters et al., 1996). Fan et al. (2014b) reported the mean RIP from 13 soil samples was 6.1 (with all discussed RIP values noted as mol.kg ${ }^{-1}$ ). Nakao et al. (2014) noted a higher mean RIP of 7.8 for 97 soil samples. Takahashi et al. (2015) reported a mean RIP of 4.1 for 7 soil samples and demonstrated that RIP was negatively correlated with a penetration coefficient $(\alpha)$, indicating that the radiocesium penetrates deeper in soils with low RIP values. A similar relationship was found between RIP values and the organic content of the soil with Takeda et al. (2014) confirming deeper radiocesium penetration in soils with elevated organic content. In particular, Takeda et al. (2014) reported a mean RIP for 46 samples of 2.4. Further, Koarashi et al. (2012a) reported a strong negative correlation $(r=-0.79, p<0.005)$ between total organic carbon (TOC) content divided by clay content (TOC/clay) and the percentage of retention of ${ }^{137} \mathrm{Cs}$, suggesting that the presence of organic matter inhibits the adsorption of ${ }^{137} \mathrm{Cs}$ on clay minerals.

Along with TOC, RIP depends on the presence of minerals having selective adsorption sites for Cs (micas, micaceous clays) (Takeda et al., 2014). Indeed, the type of clay may be more important than the total clay content as there were higher RIP values in soils containing clays from the micaceous, vermiculitic and chloritic groups (>10 mol/kg)(Takahashi et al., 2015) than in soils containing clays of amorphous and kaolinitic groups (Nakao et al., 2014). In the Fukushima region where some soils developed on volcanic ash deposits, they contain higher amounts of poorly crystalline minerals (e.g., allophane, imogolite), which do not provide these adsorption sites (Takeda et al., 2014). There have even been positive relationship between RIP and native K content which further reflects the fact that the ${ }^{137} \mathrm{Cs}$ retention ability of soil clays is controlled primarily by the amount of micaceous minerals (Nakao et al., 2014). Ultimately, owing to the variety of relationships between TOC, clay content and clay species, quantifying the dominant factors influencing RIP in the Fukushima region is more complicated than in the Chernobyl region.

The research on radiocesium deposition on soils has focussed on understanding post-deposition dynamics. In particular, understanding the RIP and concomitant fixation to soil is important to 
understand post-deposition processes with important ramifications for management. For example, owing to the strong fixation potential to soils, radiocesium will be maintained in the upper sections of undisturbed soil allowing for potential decontamination through the removal of the soil surface (e.g. top $5 \mathrm{~cm}$ ) in undisturbed sites. Further, as radiocesium is strongly fixated to fine mineral soils, it potentially may be eroded during rainfall events and its migration and transfer from hillslopes to the Pacific Ocean will be governed by the geomorphological and hydrological factors driving soil erosion, mobilization, and transport processes.

\section{Radiocesium hillslope transfers}

As radiocesium is tightly bound to soil particles, the transfer of soil-bound radiocesium can occur with the physical mobilization of soil particles during erosion processes (Yoshimura et al., 2015a). The amount of radiocesium wash-off generated by erosion processes is dependent upon the volume of soil eroded and the radiocesium concentration in the soil, with the latter being dependent on the amount of radiocesium within the soil (Yoshimura et al., 2015a). In the coastal catchments of the Fukushima Prefecture, sheetwash erosion on cultivated slopes dominates, as slope gradients on cultivated hillslopes are low and their length is insufficient to allow runoff to concentrate and generate rills or gullies (Vandaele et al., 1996).

To examine soil and radiocesium export, Yoshimura et al. (2015a) established seven Universal Soil Loss Equation (USLE) run-off plots in Kawamata Town. They examined one forest, two cultivated, two uncultivated, and two grassland sites and reported that land use is important when modelling the export of radiocesium. In particular, one uncultivated farmland plot dominated the radiocesium and sediment runoff. The farmland plots had the highest rates of erosion $\left(1 \mathrm{~kg} \mathrm{~m}^{-2}\right.$ of soil loss $)$ and ${ }^{137} \mathrm{Cs}$ export $\left(16 \mathrm{kBq} \mathrm{m}^{-2}\right)$, followed by grassland and the forest plots $\left(<0.1 \mathrm{~kg} \mathrm{~m}^{-2}\right.$ of soil loss and $<2 \mathrm{KBq} \mathrm{m}$ ${ }^{2}$ of ${ }^{137} \mathrm{CS}$ ). In particular, Yoshimura et al. (2015a) reported an exponential relationship between vegetation cover and soil loss. 
Quantifying hillslope erosion is difficult for Japanese paddy fields as they may be both sources and sinks of sediment and sediment-bound radiocesium (Tanaka et al., 2013b; Wakahara et al., 2014). When paddies are puddled for the rice growing season, they are flooded with water potentially containing suspended sediment and adsorbed radiocesium (Endo et al., 2013; Wakahara et al., 2014; Yoshikawa et al., 2014). Further, when the paddies are drained, they are directly connected to the stream network and may become a significant source of sediment and radiocesium, as water and sediments discharged from paddy fields are often transferred directly to stream systems (Wakahara et al., 2014).

Tanaka et al. (2013b) investigated the impact of contaminated irrigation water on rice paddy radiocesium inventories. Although they did not report a significant impact of irrigation water on the radiocesium inventory in the paddy, they concluded that significant rainfall events may increase radiocesium migration and transfer. In a non-hillslope erosion oriented study, Yoshikawa et al. (2014) found that the irrigation of paddy fields only contributed an additional $0.03-0.05 \%$ of ${ }^{137} \mathrm{Cs}$ to the preirrigation paddy field ${ }^{137} \mathrm{Cs}$ inventory. The authors concluded that the additional ${ }^{137} \mathrm{Cs}$ load from irrigation is negligible in comparison to the existing soil ${ }^{137} \mathrm{Cs}$ inventory.

Wakahara et al. (2014) examined the discharge of radiocesium from rice paddy fields reporting that a normally cultivated paddy field exported $1240 \mathrm{~Bq} \mathrm{~m}^{-2}$ of ${ }^{137} \mathrm{Cs}$ after puddling and $102 \mathrm{~Bq} \mathrm{~m}^{-2}$ after irrigation. Comparatively, a decontaminated paddy exported $48 \mathrm{~Bq} \mathrm{~m}{ }^{-2}$ of ${ }^{137} \mathrm{Cs}$ after puddling and $317 \mathrm{~Bq} \mathrm{~m}^{-2}$ after irrigation. Although decontamination removed $95 \%$ of the fallout radiocesium from this particular paddy, the export of radiocesium from the decontaminated paddy was greater after irrigation than the non-decontaminated paddy. The authors concluded that water inflows during events and irrigation with sediment-bound ${ }^{137} \mathrm{Cs}$ contributed to this counter-intuitive result.

There has been limited research on the radiocesium migration from forests. Kitamura et al. (2014) modelled that forest soils, which occupy a large portion of the region, export only a small fraction of soil and radiocesium. Pratama et al. (2015) modelled that subcatchments of the Abukuma River with 
greater proportions of forest coverage have the lowest radiocesium export. Nagao et al. (2013) confirmed this finding in their monitoring research through indicating that, while forest land uses cover $64 \%$ of their research catchments, they only accounted for $24 \%$ of soil and $41 \%$ of ${ }^{137} \mathrm{Cs}$ export. Although forests disproportionately contribute less radiocesium than their initial inventories, the gross amounts exported are high owing to their large area (Kitamura et al., 2014).

Fig. 7 illustrates the limited extent of direct hillslope erosion sampling in the Fukushima region. The research on hillslope erosion was located in the Abukuma catchment. This limited research reflects a similar lack of research in monsoonal regions on soil erosion owing to the difficulties in conducting complex field observation studies during intense rainfall conditions or replicating these conditions in laboratory environments. More research at the hillslope scale is important to quantify the erosion and concomitant radiocesium transfer during runoff events. Different erosion and runoff dynamics exist for each land use, complicating our understanding of the detachment and transfer of contaminated sediments, particularly in catchments with mixed land use (Kinouchi et al., 2015). As radiocesium is bound to soil, its initial mobilization and transfer will be directly dependent on the various factors governing soil erosion (for example see Morgan et al. (1998); Nearing et al. (1989); Renard et al. (1991)). Thoroughly characterizing potential soil erosion processes from different sources at the hillslope scale is thus fundamental to understanding the potential transfer from hillslopes to the Pacific Ocean. In particular, more research is required to properly characterize the dominant sources of particulate radiocesium in the Fukushima region and the relative contribution of these sources to radiocesium fluxes to the Pacific Ocean.

\section{Factors influencing riverine radiocesium transfer}

As radiocesium mobilized from hillslopes and transported downstream is selectively attached to the finest eroded soil particles (Kinouchi et al., 2015), it is important to develop a quantitative understanding of the particle size redistribution of radiocesium to predict potential contamination of downstream areas that are more densely populated and not-affected by the initial fallout (Kinouchi 


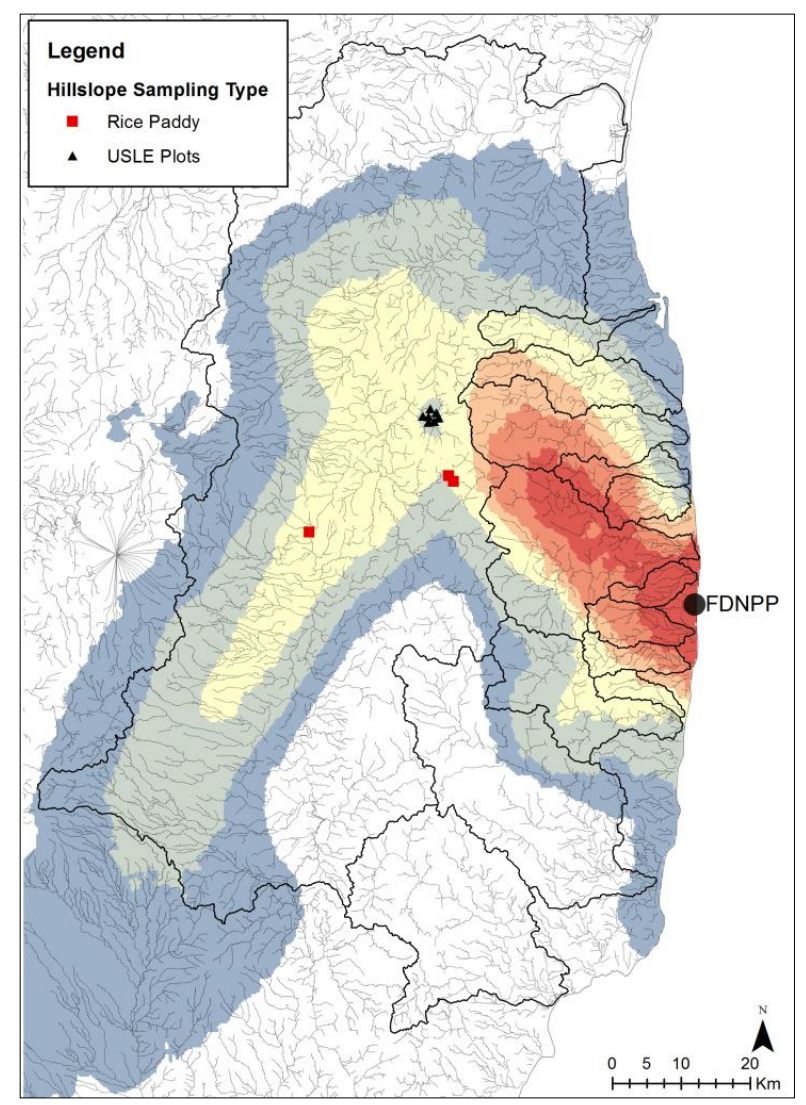

Figure 7. Sample locations for research examining hillslope radiocesium transfer with USLE-based and calculations of suspended sediment yields form rice paddy fields.

transfer farther and possibly stored longer) and also potential storage within stream systems (e.g. coarse particles are deposited sooner). Along with the particulate fraction, it is important to understand the dissolved/particulate partitioning of transported radiocesium in rivers and streams.

Radiocesium is transferred in both dissolved and particulate fractions that behave differently.

Examining the rainfall/climate is also important to determine the impacts of climate on radiocesium

427 transfer and storage. Importantly the potential storage of radiocesium between hillslopes and the

428 Pacific Ocean may become a significant focal point of future management efforts. Prior to examining research that quantifies radiocesium transfers and export from the coastal catchments, each of these dynamics impacting radiocesium transfers will be discussed. 
In the fallout affected catchments, the main radioactive pollution plume is drained by the Abukuma

432 River, along with several small coastal catchments (Fig. 3). The majority of research has focused on

433 understanding the transfer of fallout contamination in the Abukuma River basin (Fig. 8). For the

434 smaller coastal catchments, there has been a focus of research in the Niida and Mano rivers with

435 decreasing research in the catchments close to and south of the FDNPP. In particular there has been

436 limited research published on the catchments with the highest mean radiocesium inventories (the

437 Maeda, Kuma, Ukedo and Ota catchments).

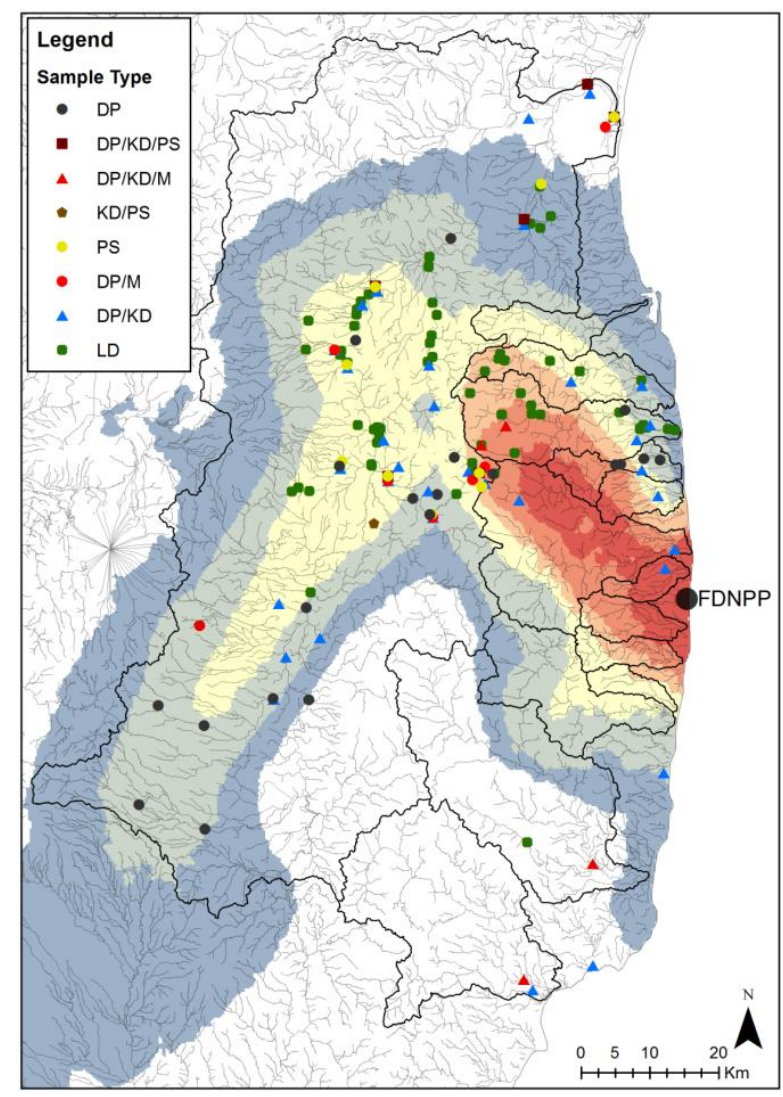

Figure 8. Location of stream sampling locations for samples examining dissolved/particulate (DP) fractions and their distribution coefficient (KD), particle size (PS), monitoring (M), and lag deposits (LD).

\subsection{Radiocesium distribution coefficient (dissolved/particulate)}

To quantify radiocesium migration in catchments, it is necessary to understand the ratio of particulate and dissolved radiocesium transported in river systems. Dissolved and particulate-bound radiocesium migrate differently in waterways and their ratio provides fundamental information for 
understanding future migration (Yoshimura et al., 2015b). The dissolved/suspended partitioning of radionuclides is typically described with a distribution coefficient, $\mathrm{K}_{\mathrm{d}}$, and is expressed as a ratio of radiocesium activity concentration in particulate and dissolved fractions under equilibrium conditions (Ueda et al., 2013).

In samples from the Abukuma River, Sakaguchi et al. (2015) reported that the particulate fraction transported $80 \%$ of ${ }^{137} \mathrm{Cs}$ (Table 3). Conversely, Tsuji et al. (2014) indicated that in the Abukuma and Ota catchments, only $64 \%$ of the radiocesium was transported with the particulate fraction. When examining sediments across the fallout impacted region, Yoshimura et al. (2015b) found that between $58-100 \%$ of radiocesium was transported with the particulate fraction, with the exclusion of one estuary site. Similarly, Yoshikawa et al. (2014) reported that between $60-95 \%$ of radiocesium was transported with the particulate fraction in three small subcatchments $\left(<0.1 \mathrm{~km}^{2}\right)$ of the Abukuma River.

Differences between these results are likely related to the timing of sampling in relation to significant rainfall events. For example, in the Same and Natsui catchments, Nagao et al. (2013) observed that in normal flow conditions, the particulate fraction transported $40 \%$ of the ${ }^{137} \mathrm{Cs}$, compared to $100 \%$ during a significant rainfall event (i.e. Typhoon Roke). Ueda et al. (2013) also reported significant differences between flood and base flow conditions with the particulate partition contributing over $90 \%$ of radiocesium in the Niida River during Typhoon Roke. In this catchment, the particulate fraction only accounted for $40 \%$ of the radiocesium migration in base flow conditions. In addition, Shinomiya et al. (2014) found that $92-97 \%$ of radiocesium is transferred with the particulate fraction during significant rainfall events (Typhoon Guchol), compared to between $12-96 \%$ in base flow. From modelling research, Mori et al. (2014), determined that the particulate fraction transported more than $95 \%$ of the ${ }^{137}$ Cs, slightly above the range calculated by Yamashiki et al. (2014) (82-93\%). This research clearly demonstrates that the particulate fraction dominates the transfer of radiocesium in the Fukushima region during major rainfall events. 
467 Differences between the dissolved/particulate radiocesium partitioning may also be influenced by 468 the time elapsed since the FDNPP accident. For example, in the Niida catchment, Nagao et al. (2014) 
Table 3. Summary of research examining radiocesium in particulate/dissolved and $K_{d}$

\begin{tabular}{|c|c|c|c|c|c|}
\hline Author(s) & Catchment(s) & Sampling Period & Radionuclide(s) & $\begin{array}{l}\text { Particulate Fraction of } \\
\text { transported }{ }^{137} \text { Cs (\%) }\end{array}$ & Average $K(d)$ \\
\hline Nagao et al. (2013) & Same / Natsui & July 2011 - Dec. 2011 & ${ }^{134} \mathrm{Cs} \&{ }^{137} \mathrm{Cs}$ & $\begin{array}{l}99 \text { Flood Conditions } \\
33 \text { Base Flow }\end{array}$ & $2.5 \times 10^{6}$ \\
\hline Nagao et al. (2014) & Niida & May 2011 - Nov. 2012 & ${ }^{134} \mathrm{Cs} \&{ }^{137} \mathrm{Cs}$ & $\begin{array}{l}47 \text { (Before Sept. 2011) } \\
84 \text { (After Sept. 2011) }\end{array}$ & N/A \\
\hline Sakaguchi et al. (2015) & Abukuma & June 2011 - Dec. 2012 & ${ }^{137} \mathrm{Cs}$ & 80 & $8.8 \times 10^{5}$ \\
\hline Shinomiya et al. (2014) & $\begin{array}{l}\text { Experimental Catchment } \\
\text { (Abukuma) }\end{array}$ & June 2012 & ${ }^{134} \mathrm{Cs},{ }^{137} \mathrm{Cs}$ & $\begin{array}{l}\text { 92-97 Flood Conditions } \\
\text { 12-96 Base Flow }\end{array}$ & N/A \\
\hline Tsuji et al. (2014) & Abukuma, Ota & Sept. 2012 - May 2013 & ${ }^{134} \mathrm{Cs} \&{ }^{137} \mathrm{Cs}$ & 64 & N/A \\
\hline Ueda et al. (2013) & Niida & July 2011 - Nov. 2011 & ${ }^{134} \mathrm{Cs} \&{ }^{137} \mathrm{Cs}$ & $\begin{array}{l}>90 \text { Flood Conditions } \\
40 \text { Base Flow }\end{array}$ & $3.5 \times 10^{5}$ \\
\hline Yamashiki et al. (2014) & Abukuma & June 2011 - May 2012 & ${ }^{134} \mathrm{Cs} \&{ }^{137} \mathrm{Cs}$ & $82-93$ & N/A \\
\hline Yoshikawa et al. (2014) & Abukuma & April 2012 - Sept. 2012 & ${ }^{137} \mathrm{Cs}$ & $\begin{array}{l}\text { 60-83 Flood Conditions } \\
\text { 69-95 Base Flow }\end{array}$ & $\begin{array}{l}1.2 \times 10^{5} \text { Base } \\
10.6 \times 10^{5} \text { Event }\end{array}$ \\
\hline Yoshimura et al. (2015b) & $\begin{array}{l}\text { Abukuma, Mano, Same, } \\
\text { Fujiwara, Niida, Ota, } \\
\text { Odaka, Asami, Ukedo, }\end{array}$ & Dec. 2012 & ${ }^{134} \mathrm{Cs} \&{ }^{137} \mathrm{Cs}$ & $58-100^{a}$ & $3.6 \times 10^{5}$ \\
\hline
\end{tabular}


reported that the particulate fraction averaged $47 \%$ between May and September 2011 compared to 84\% between December 2011 and November 2012. The differences were attributed to rainfall and declining availability of leachable sources of radiocesium that were likely washed off in greater concentrations early after the accident. When researching dissolved radiocesium fractions in stream and ground water, Iwagami et al. (Submitted) also reported a fast flush of radiocesium before October 2011, resulting from the initial wash-off, followed by a slow decline in radiocesium concentrations. Moving forward, it is likely that the particulate phase will constitute a greater proportion of the radiocesium transfer.

In the Niida catchment, Ueda et al. (2013) reported that the mean $K_{d}$ was $3.5 \times 10^{5}$ (Table 3 ). Yoshimura et al. (2015b) calculated a very similar mean $K_{d}$ of $3.6 \times 10^{5}$ when comparing the particulate material sampled from time-integrated samplers (Phillips et al., 2000) and water sampled with a vacuum pump sampler. Nagao et al. (2013) demonstrated that the $K_{d}$ range in the Same and Natsui Rivers was between $0.4 \times 10^{6}-5.0 \times 10^{6}$. Yoshikawa et al. (2014) reported that the $K_{d}$ in three small $\left(<1.2 \mathrm{~km}^{2}\right)$ was $1.2 \times 10^{5}$ in base flow compared to $10.6 \times 10^{5}$ in event conditions. Sakaguchi et al. (2015) indicated the $K_{d}$ in the Abukuma River was $8.8 \times 10^{5}$. In general, these results are an order of magnitude greater than those reported by the International Atomic Energy Agency after the Chernobyl accident $\left(2.9 \times 10^{4}\right)$ (UNSCEAR, 2000) indicative of a greater percentage of particulatebound radiocesium migrating through these catchments compared to those sampled in areas impacted by fallout from the Chernobyl accident. In Ukrainian rivers with similar volumes of total suspended solids as in Fukushima rivers, the dissolved fraction was found to contain $\sim 75 \%$ of the sampled ${ }^{137}$ Cs (1-2 y post-accident) (Sansone et al., 1996). Although a significant component of radiocesium migrates with the dissolved fraction in normal flow conditions in the Fukushima region, it contributes only a limited amount to the total radiocesium migration to downstream areas (Kinouchi et al., 2015). The challenge is that the particulate radiocesium concentrations are often irregular and driven by suspended solid fluctuations resulting from heavy precipitation (Tsuji et al., 
2014) and it is difficult and costly to continuously monitor suspended solids, particularly during high flow conditions.

Ueda et al. (2013) demonstrated a high correlation between the discharge of radiocesium and fluvial water discharge. Correlations were also found between particulate/dissolved radiocesium concentrations and catchment radiocesium inventories, suggesting that it may be possible to predict radiocesium concentrations (Yoshimura et al., 2015b). As this correlation is empirical and may change owing to regional hydro-meteorological dynamics, further research is required before using this relationship directly in modelling approaches. Importantly, $K_{d}$ was found to be related to the proportion of large particles (e.g. low clay content), the clay mineralogy of small particles, and the aqueous phase cation concentration (Fan et al., 2014a). As radiocesium primarily bound to fine sediment particles (Yamaguchi et al., 2012), it is important to understand the relationship between radiocesium and particle size for modelling radiocesium transfer at larger scales.

\subsection{Radiocesium particle size distributions}

The fine soil fraction, to which radiocesium is bound, is preferentially eroded at the hillslope scale (mean particle size $=25.5 \mu \mathrm{m}$ ) (Yoshimura et al., 2015a). This fraction (e.g. silt and clay) is also preferentially transported farther distances owing to a smaller settling velocity (Iwasaki et al., 2015) resulting in the accumulation of radiocesium in downstream areas potentially unaffected by the initial fallout (Tanaka et al., 2014). Indeed the distribution of radiocesium with regards to particle size will have a significant impact on the radiocesium deposition in downstream areas. It is therefore important to examine whether sediment generation and transport processes impact the radiocesium fixation to fine particles.

River sediments were found to have a high ${ }^{137}$ Cs adsorption capacity (Fan et al., 2014a). Multiple studies demonstrated that radiocesium concentrations were elevated in the fine particle size fractions (Fan et al., 2014a; Sakaguchi et al., 2015; Tanaka et al., 2015; Tanaka et al., 2014). Sakaguchi et al. (2015) found that the maximum ${ }^{137} \mathrm{Cs}$ concentration in suspended sediment was found in the 
silt particle size fraction $(3-63 \mu \mathrm{m})$. This result was also reported in Fan et al. (2014a). In the former case, ${ }^{137} \mathrm{Cs}$ in each fraction did not demonstrate any systematic variation across multiple sampling sites (Sakaguchi et al., 2015). In the latter, Fan et al. (2014a) found that there was a weak relationship between particle size and radiocesium for fine sediment $(<63 \mu \mathrm{m})$, though a stronger relationship was derived for the coarser grain fractions (e.g. $>63 \mu \mathrm{m}$ ).

The sorption of radiocesium to sediments was found to be directly related to their physical-chemical properties, including cation exchange capacity, organic matter content and mineralogy (Fan et al., 2014a). What was unexpected with these findings was that the radiocesium concentrations were not always enriched in the fine clay material $(<3 \mu \mathrm{m})$. A below expected quantity of radiocesium in the fine clay material was also reported by Tanaka et al. (2014) who found that the silt and sand fractions transported $95 \%$ of the sediment-sorbed radiocesium. This study did find an enrichment of ${ }^{137} \mathrm{Cs}$ in the clay material, though it was found to only constitute a small proportion of the sampled bedload material. Fan et al. (2014a) also reported a low clay mineral content in the $<2 \mu \mathrm{m}$ particle size fraction. The lack of radiocesium enrichment in the finest particle size fraction may be the result of sampling technique (e.g. sampling bed load material) or other fluvial processes that may result in the majority of very fine material being exported from the catchment.

For modelling and management of radiocesium transfers in the contaminated catchments, it may be silt, rather than clay that requires emphasis. For example, silt was found to be the significant source of bed contamination (excluding initial fallout) whereas during later stages of rainfall flow events, clay materials were found to be the dominant supply of ${ }^{137} \mathrm{Cs}$ to the lower river reaches (Kurikami et al., 2014). Further characterization of the relationship between radiocesium and particle size is fundamental for understanding radiocesium transfer and storage in fallout affected catchments.

\subsection{Radiocesium mobilization: Rainfall regime}

Rainfall is the driving mechanism behind soil erosion by water (Nearing et al., 1989; Wischmeier and Smith, 1958). The regional climate in conjunction with the topography of the fallout impacted region 
exacerbates radiocesium transfer. The catchments of the Fukushima Prefecture are mountainous and characterized with a steep topography (Kinouchi et al., 2015; Minoura et al., 2014). The temperate/monsoonal climate results in high seasonal and annual precipitation including significant runoff events generated from snowmelt and intense rainfall from typhoons (Evrard et al., 2013; Yamashiki et al., 2014). In the Fukushima region, the annual precipitation is three-fold greater than in Chernobyl, resulting in a more rapid radiocesium washoff (Tsuji et al., 2014). This climate is one of the fundamental mechanisms driving the migration and transfer of radiocesium throughout the catchments that received the original fallout (Evrard et al., 2013).

Evrard et al. (2013) demonstrated that the region is highly reactive to both rainfall and snow fall events. The authors demonstrated that there is a significant export of contaminated material from coastal rivers to the Pacific Ocean. Chartin et al. (2013) found that the combination of rainfall and snowmelt events results in a progressive migration of sediment bound radiocesium to the Pacific Ocean. This sediment-based sampling clearly demonstrated that there has been a significant dispersion of contaminated sediments in the 20 months after the FDNPP accident (Chartin et al., 2013). These authors highlight a massive, rapid and episodic transfer of radiocesium resulting from the climate in general and the snowmelt/typhoon cycle in particular. Yamashiki et al. (2014) also reported two significant runoff peaks in their research, one clearly coinciding with the snowmelt in late spring (April-May) and the other coinciding with typhoons.

Overall, the literature clearly demonstrates that the majority of soil erosion and concomitant radiocesium migration, coincides with extreme rainfall-runoff events (Minoura et al., 2014; Mouri et al., 2014; Nagao et al., 2013; Onishi et al., 2014). In fact, most sediment and radiocesium migration is thought to occur during short flood events that may occur 1-2 times per year (Yamaguchi et al., 2014). This importance of flooding and rainfall was incorporated by Kitamura et al. (2014) who only modeled sediment migration when the flow rate is 10 times greater than the average annual flow. 
In particular, the typhoons in the fallout impacted region transfer massive amounts of sediment and radiocesium. For example, Typhoon Roke (Sept. 2011) destroyed paddy banks (Wakahara et al., 2014) and resulted in mud depositions that were $\sim 10 \mathrm{~cm}$ thick (Minoura et al., 2014). Yamashiki et al. (2014) estimated that Typhoon Roke mobilized and transferred $6.18 \mathrm{TBq}$, or $61 \%$ of the total radiocesium load to the coastal areas during their observation period. Kinouchi et al. (2015) reported that three major flow events were responsible for the migration of $43 \%$ of the sediment between June 2011 and Dec. 2012. Nagao et al. (2013) demonstrated that radiocesium concentrations were an order of magnitude higher during high flow conditions after Typhoon Roke, which also resulted in particulate transport of radiocesium being $100 \%$ compared to $21-56 \%$ in baseflows. The authors concluded that these heavy rainfall events are one of the important drivers of radiocesium migration from catchments to the coast resulting for between $30-50 \%$ of the annual radiocesium coastal transfer. Ultimately, extreme rainfall events are fundamental to the migration of sediments and radiocesium from the hillslopes to the Pacific Ocean.

\subsection{Radiocesium storage: Reservoirs and dams}

Not all mobilized sediment and radiocesium is exported to the Pacific Ocean. The migration of sediment, particularly coarse particle size fractions, occurs over longer temporal scales. Further, anthropogenic alterations to riverine morphology, such as reservoirs and dams, further delay the migration and transfer of sediment and radiocesium downstream (Kurikami et al., 2014). Reservoirs not only delay the migration of radiocesium and sediments, they also may act as a major sinks and storage (Evrard et al., 2014a; Evrard et al., 2013) as only a select fraction of radiocesium is transferred downstream, predominantly the dissolved or clay-bound fractions (Onishi et al., 2014). These reservoirs may also act as sources of contaminated sediment during water releases.

Chartin et al. (2013) reported a significant layer of sediments with high radiocesium concentrations deposited behind a reservoir in the upper Ota River. Kitamura et al. (2014) indicated that $10^{4} \mathrm{t}$ of sediment and $10 \mathrm{TBq}$ of ${ }^{137} \mathrm{Cs}$ were transferred into the Ogaki Dam on the Ukedo River which 

buffered the downstream transfer of radiocesium. Kurikami et al. (2014) reported that the sand particle size fraction was completely contained within the Ogaki Dam, with only $5 \%$ of the silt and $50 \%$ of the clay fractions transferred downstream. Similarly, Yamada et al. (2015) found that practically all of the silt and sand are deposited within the Ogaki Dam reservoir, with the sand being deposited near the entrance of the reservoir and the silt being more uniformly distributed. Approximately a third of the clay fraction was modelled to be exported downstream from this reservoir (Yamada et al., 2015).

Management of the dams and reservoirs may have a significant impact on radiocesium migration downstream. Mouri et al. (2014), Yamada et al. (2015) and Kurikami et al. (2013) demonstrated that reservoir management could assist in the control of radiocesium fluxes. The challenge with the management of these reservoirs in the temperate/monsoonal climate in the Fukushima region is that occasional water releases are required for their safe operation. Evrard et al. (2014a) indicated these dam releases could enhance the natural migration of radiocesium downstream and may become a significant factor controlling the downstream transfer of sediment and radiocesium in these anthropogenically modified catchments. In the Fukushima Prefecture, there are 10 significant dams and over a 1,000 reservoirs for both agricultural and surface water management (Yamada et al., 2015). Understanding the radiocesium deposition and migration within these water storages is important for understanding potential contamination of downstream regions, particularly cultivated rice paddy systems.

To quantify radiocesium transfer from hillslopes to the Pacific Ocean, it is necessary to characterize riverine radiocesium dynamics within the climatic context. Radiocesium may be transferred in particulate or dissolved fractions, and the particle size distribution of particulate radiocesium will either facilitate its transfer or potential downstream storage during rainfall and snowmelt runoff events that drive the majority of radiocesium migration. Understanding these dynamics, particularly in the catchments with the highest mean radiocesium activities will be of increasing importance 
moving forward. In particular, characterizing interrelationships between typhoons and other rainfall/runoff events along with radiocesium particle size and distribution coefficients allows researchers to determine whether radiocesium may be stored within a catchment after its hillslope mobilization or whether it is ultimately transferred to the Pacific Ocean.

\section{Quantifying radiocesium transfers from hillslopes to the Pacific Ocean}

Radiocesium dynamics within riverine environments are inherently complex. Accordingly, there are a variety of factors governing radiocesium transfer in the region affected by the FDNPP accident. Quantifying radiocesium transfers requires in-stream sampling and monitoring stations or complex desktop sediment modelling. Publications reviewed for this section focus on catchment scale radiocesium transfers and will be subdivided into monitoring and modelling research. Table 4 lists these two approaches to quantifying radiocesium transfers in the Fukushima coastal catchments while Fig. 8 includes the locations of the monitoring stations. Similarly to the research on the factors influencing riverine radiocesium transfers above, the majority of modelling research occurs within the Abukuma River catchment. There is limited monitoring and modelling research in the smaller coastal catchments, particularly the catchments to the south and in close proximity to the FDNPP.

\subsection{Monitoring radiocesium catchment scale transfers}

Direct monitoring of radiocesium sampled within rivers over several months or years provides data required to quantify radiocesium exports from catchments. For example, relationships between total suspended solid and radiocesium quantities within river water/sediment samples may be quantified and extrapolated over longer temporal periods. Although there are limitations, this monitoring 
Table 4. Summary modelling and monitoring results

\begin{tabular}{|c|c|c|c|c|c|c|c|}
\hline Author(s) & Type & Catchment(s) & $\begin{array}{l}\text { Area } \\
\left(\mathrm{km}^{2}\right)\end{array}$ & Period & $\begin{array}{l}\text { Radionuclides } \\
\text { (Particulate (P)- } \\
\text { Dissolved (D)) }\end{array}$ & Export (TBq) & $\begin{array}{l}\text { Catchment } \\
\text { Inventory } \\
\text { Exported (\%) }\end{array}$ \\
\hline $\begin{array}{l}\text { Iwasaki et al. } \\
\text { (2015) }\end{array}$ & Modelling & Abukuma (downstream reach) & 31 & September 2011 & ${ }^{137} \mathrm{Cs}(\mathrm{P})$ & 3.29 & $\mathrm{n} / \mathrm{a}$ \\
\hline $\begin{array}{l}\text { Kinouchi et al. } \\
\text { (2015) }\end{array}$ & Modelling & $\begin{array}{l}\text { Abukuma (Kuchibuto } \\
\text { subcatchment) }\end{array}$ & 140 & $\begin{array}{l}\text { June } 2011 \text { - December } \\
2012\end{array}$ & ${ }^{137} \mathrm{Cs}(\mathrm{P})$ & 0.274 & 0.8 \\
\hline $\begin{array}{l}\text { Kitamura et al. } \\
\text { (2014) }\end{array}$ & Modelling & $\begin{array}{l}\text { Abukuma, Ukedo, Niida, Maeda, } \\
\text { Kuma, Ota, Mano, Kido, Odaka, } \\
\text { Tomioka, Natsui, Same, Ide, Uda }\end{array}$ & 8,352 & $\begin{array}{l}\text { Annually for the initial } \\
\text { years after the } \\
\text { accident }\end{array}$ & ${ }^{137} \mathrm{Cs}(\mathrm{P})$ & 8.4 & 1.0 \\
\hline $\begin{array}{l}\text { Kurikami et al. } \\
\text { (2014) }\end{array}$ & Modelling & Ukedo (Okagi Dam) & $\mathrm{n} / \mathrm{a}$ & September 2013 & ${ }^{137} \mathrm{Cs}$ (D\&P) & $0.86^{\mathrm{a}}$ & $\mathrm{n} / \mathrm{a}$ \\
\hline $\begin{array}{l}\text { Mori et al. } \\
\text { (2014) }\end{array}$ & Modelling & Un-named reservoir & 15 & $\begin{array}{l}\text { March } 2011 \text { - } \\
\text { December } 2013\end{array}$ & ${ }^{137} \mathrm{Cs}(\mathrm{P})$ & $\mathrm{n} / \mathrm{a}$ & $<5.0$ \\
\hline $\begin{array}{l}\text { Mouri et al. } \\
\text { (2014) }\end{array}$ & Modelling & Tone (Kusaki Dam) & 254 & $2010-2090$ & ${ }^{137} \mathrm{Cs}(\mathrm{P})$ & $900 \mathrm{~Bq} / \mathrm{kg}^{\mathrm{b}}$ & $\mathrm{n} / \mathrm{a}$ \\
\hline $\begin{array}{l}\text { Nagao et al. } \\
\text { (2013) }\end{array}$ & Monitoring & Natsui, Same & $749 / 600$ & $\begin{array}{l}\text { March } 2011 \text { - } \\
\text { December. } 2011\end{array}$ & ${ }^{134} \mathrm{Cs},{ }^{137} \mathrm{Cs}$ (D\&P) & 0.04 & $\mathrm{n} / \mathrm{a}$ \\
\hline $\begin{array}{l}\text { Pratama et al. } \\
\text { (2015) }\end{array}$ & Modelling & Abukuma & 5,172 & $\begin{array}{l}\text { August 2011-May } \\
2012+\text { future } \\
\text { scenarios }\end{array}$ & ${ }^{134} \mathrm{Cs}^{\prime}{ }^{137} \mathrm{Cs}$ (D\&P) & $\sim 12$ & $2 \%$ \\
\hline $\begin{array}{l}\text { Shinomiya et al. } \\
\text { (2014) }\end{array}$ & Monitoring & $\begin{array}{l}\text { Experimental Catchment } \\
\text { (Abukuma) }\end{array}$ & 0.01 & June 2012 & ${ }^{134} \mathrm{Cs},{ }^{137} \mathrm{Cs}$ & $115\left(\mathrm{~Bq} \mathrm{~m}^{2}\right)$ & 0.07 \\
\hline $\begin{array}{l}\text { Ueda et al. } \\
\text { (2013) }\end{array}$ & Monitoring & Niida (Wasriki and Hiso Rivers) & $<5$ & July-November 2011 & ${ }^{134} \mathrm{Cs},{ }^{137} \mathrm{Cs}$ (D\&P) & 0.03 & 0.4 \\
\hline $\begin{array}{l}\text { Yamada et al. } \\
\text { (2015) }\end{array}$ & Modelling & Ukedo (Okagi Dam) & $\mathrm{n} / \mathrm{a}$ & $\begin{array}{l}\text { September } 2013 \text { \& } \\
\text { average flood }\end{array}$ & ${ }^{137} \mathrm{Cs}(\mathrm{D} \& \mathrm{P})$ & $0.07 \& 0.35$ & $\mathrm{n} / \mathrm{a}$ \\
\hline $\begin{array}{l}\text { Yamaguchi et al. } \\
\text { (2014) }\end{array}$ & Modelling & $\begin{array}{l}\text { Abukuma, Ukedo, Niida, Maeda, } \\
\text { Kuma, Ota, Mano, Kido, Odaka, } \\
\text { Tomioka, Natsui, Same, Ide, Uda }\end{array}$ & 8,352 & $\begin{array}{l}\text { March } 2011 \text { - March } \\
2012+\text { future } \\
\text { scenarios }\end{array}$ & ${ }^{137} \mathrm{Cs}(\mathrm{P})$ & $02.3-6.5^{c}$ & $0.5-7.5^{c}$ \\
\hline $\begin{array}{l}\text { Yamashiki et al. } \\
\text { (2014) }\end{array}$ & Monitoring & Abukuma & 5,172 & June 2011 - May 2012 & ${ }^{134} \mathrm{Cs},{ }^{137} \mathrm{Cs}(\mathrm{P})$ & 10.08 & 1.1 \\
\hline
\end{tabular}


approach is a direct method to quantify radiocesium transfer from catchments and ultimately to the Pacific Ocean.

Most of the direct radiocesium monitoring within catchments occurs at the smaller subcatchment scale. For example, Shinomiya et al. (2014) monitored radiocesium discharge from a small forested catchment $\left(0.012 \mathrm{~km}^{2}\right)$ in Abukuma River basin. The authors found that maximum rainfall intensity and runoff coincided with the maximum radiocesium $\left(3.9 \mathrm{~Bq} \mathrm{~L}^{-1}\right)$ and suspended solid export. During the receding limb of the hydrograph, radiocesium transfers concentrations dropped sharply. In total, $115 \mathrm{~Bq} \mathrm{~m} \mathrm{~m}^{-2}$ was exported from this experimental catchment or $0.07 \%$ of the initial radiocesium inventory, indicative of a negligible radiocesium transfer from this forested catchment during a typhoon event.

Ueda et al. (2013) conducted regression analyses to relate radiocesium to river discharge at two sampling locations in the upper Niida catchment between March 15 and December 31, 2011. They estimated that $0.045 \mathrm{TBq}$ and $0.020 \mathrm{TBq}$ were exported from the Hiso and Wariki Rivers catchments, respectively. This equated to $0.5 \%$ of the radiocesium inventory of the Hiso catchment and $0.3 \%$ of the Wariki River catchment. Although each catchment had different land uses, their proportional radiocesium export were similar.

Nagao et al. (2013) calculated radiocesium export from the Natsui and Same Rivers catchments, south of the FDNPP. They quantified radiocesium flux by multiplying mean monthly discharge by the

${ }^{137} \mathrm{Cs}$ concentrations and time. They determined that 0.003 and $0.005 \mathrm{TBq} \mathrm{y}^{-1}$ of ${ }^{137} \mathrm{Cs}$ were exported from the Natsui and Same Rivers, respectively. They also indicated that $30-50 \%$ of their estimated 10 month ${ }^{137}$ Cs export occurred during Typhoon Roke.

To our knowledge, there has only been one current study published quantifying the transfer of radiocesium from a large catchment to the Pacific Ocean. Yamashiki et al. (2014) used in-stream samplers to collect suspended sediment along with turbidity meters and pressure transducers to calculate suspended sediment fluxes from the Abukuma River catchment to the Pacific Ocean. The 
authors estimated that $\sim 10$ TBq of radiocesium was exported to the Pacific between June 2011 and May 2012. This amounted to $\sim 1 \%$ initial estimated catchment inventory. This direct transfer of sediment from hillslopes through the Abukuma catchment to the Pacific Ocean was within the same order of magnitude of the direct leakage from the FDNPP to the ocean on August 21, 2013 (24 TBq) (Yamashiki et al., 2014) clearly demonstrating the importance of quantifying the riverine transfer of radiocesium to the Pacific Ocean.

\subsection{Modelling radiocesium catchment scale transfers}

Quantifying catchment scale radiocesium transfers with modelling approaches requires a variety of model inputs along with calibration and validation data (often obtained from direct river monitoring). The challenge for researchers when quantifying catchment radiocesium fluxes is incorporating the fundamental radiocesium transfer dynamics required to populate models without over parameterizing radiocesium dynamics. Often, the scale of the research catchment controls the breadth of radiocesium dynamics incorporated into individual models. Similarly to the monitoring studies, desktop models have been performed at various scales, from upstream catchments to large river basins to quantify radiocesium transfer directly to the Pacific Ocean.

For an upstream catchment of the Abukuma River system, Kinouchi et al. (2015) developed a complex model incorporating evaporation, evapotranspiration, infiltration, surface and subsurface runoff along with groundwater, overland and river flow. The authors coupled hydrological processes and energy transfer within a catchment along with interactions between surface water and groundwater. Importantly, they modelled the hydrological processes for paddy fields, including irrigation, ponding, drainage and seepage to nearby channels. Their model also incorporated season variation in vegetation. The authors reported that after $30 \mathrm{y}$, the catchment inventory of ${ }^{137} \mathrm{Cs}$ will be reduced to $39 \%$ of the initial inventory (Kinouchi et al., 2015). They reported that between September 2011 and December 2012, 0.274 TBq of ${ }^{137}$ Cs was exported from the Kuchibuto River catchment or less than $1 \%$ of the initial ${ }^{137} \mathrm{Cs}$ fallout. 
Several studies modelled sediment and radiocesium deposition in reservoirs of the region. Mouri et al. (2014) examined radiocesium inputs to the Kusaki Dam reservoir on the edge of the fallout affected region. The authors incorporated mixed-particle size distributions into a sediment transport equation to determine sedimentation and concomitant ${ }^{137} \mathrm{Cs}$ deposition in the reservoir. The authors included 10 different particle size fractions into their model. They reported that the wash load (particle size $\leq 0.2 \mathrm{~mm}$ ) contributed little to reservoir siltation and predicted that $3.4 \mathrm{Mt} / \mathrm{y}$ of sediment were deposited in the catchment with $900 \mathrm{~Bq} / \mathrm{kg}$ of ${ }^{137} \mathrm{Cs}$. For the future, they predicted that sediment deposition would increase to $\sim 3.65 \mathrm{Mt} / \mathrm{y}$ with ${ }^{137} \mathrm{Cs}$ activities of $120 \mathrm{~Bq} / \mathrm{kg}$.

Mori et al. (2014) modelled ${ }^{137}$ Cs dynamics in an unnamed reservoir catchment between March 2011 and December 2013. In particular, they developed an integrated model incorporating fully coupled radionuclide behaviour in a channel, overland and subsurface three dimensional (3D), physics-based model. The authors demonstrated that the majority of radiocesium was transported with the particulate fraction (>95\%). Their 3D model indicated that radiocesium was predominantly eroded from steep hillslopes in close proximity to the stream network with the majority of deposition occurring at the entrance of the reservoir. The authors determined that the total ${ }^{137} \mathrm{Cs}$ discharge with both sediment and dissolved fractions was $<5 \%$ of the initial fallout inventory indicating the majority of the fallout radiocesium remained in the dammed catchment.

Kitamura et al. (2014) reported the results from the application of the Time-dependent Onedimensional Degradation and Migration (TODAM) model in the Ukedo Catchment. This model is also outlined in Kurikami et al. (2014) and discussed in Kitamura et al. (2015). The TODAM model incorporates the deposition and re-suspension of sediment along with the potential desorption/adsorption of radiocesium within sub-models. It simulates the movement of three sediment particle size fractions (sand/silt/clay). The authors determined that ${ }^{137} \mathrm{Cs}$ concentrations were lower than the drinking water limit after approximately $4 \mathrm{~d}$ following a significant rainfall event (Kurikami et al., 2014). The authors also reported that $0.86 \mathrm{TBq}$ of ${ }^{137} \mathrm{Cs}$ was deposited in the Okagi 
Dam Reservoir (Kitamura et al., 2014), which is only one order of magnitude less than the total ${ }^{137}$ Cs export to the Pacific Ocean from 14 coastal catchments.

716

717

Yamada et al. (2015) also modelled radiocesium dynamics for the Ogaki Dam with the Nay2D model (Shimizu, 2003) to examine the influence of countermeasures such as controlling the reservoir volume on ${ }^{137} \mathrm{Cs}$ export. This paper was also discussed in Kitamura et al. (2015). The authors compared a September 2013 flood event to the long-term average flood event and calculated ${ }^{137} \mathrm{Cs}$ deposition and export. For the September 2013 flood, they modelled that 0.16 TBq was deposited in the Ogaki Dam with $0.07 \mathrm{TBq}$ exported downstream. These transfers were low compared to the average yearly flood which was modelled to deposit $0.55 \mathrm{TBq}$ and export $0.35 \mathrm{TBq}$.

Finally, several studies quantified the export of radiocesium from catchments to the Pacific Ocean by focusing on lower river reaches or by modelling major catchments affected by fallout. Iwasaki et al. (2015) investigated ${ }^{137} \mathrm{Cs}$ dynamics in a downstream reach of the Abukuma River. They incorporated a Rouse number threshold within their complex model to determine whether sediments are exported from the reach or deposited. The authors reported there is significant deposition of contaminated sediments on river floodplains. The authors highlighted the potential of using a Rouse number threshold to determine the location of radiocesium deposition within the catchment to target decontamination activities. In particular, they suggested that the floodplains and inner areas of river bends can be contaminated at the end of significant rainfall events. Even whilst incorporating deposition within the $31 \mathrm{~km}$ reach, the authors reported that $98 \%$ of ${ }^{137} \mathrm{Cs}$ (or $3.2 \mathrm{TBq}$ ) was transferred downstream towards the Pacific Ocean.

For the entire Abukuma River catchment, Pratama et al. (2015) developed a multiple compartmental model that incorporated the complexity of radiocesium export from forest, urban and agricultural land uses. The authors' model accurately predicted seasonal patterns of radiocesium fluxes in the Abukuma catchment. The model was calibrated with monitoring data between August 2011 and May 2012 and then forecasted radiocesium migrations for the next $100 \mathrm{y}$. The authors found that in total 
$155 \mathrm{TBq}$ of radiocesium will be exported from the Abukuma catchment over the next century. Based on their results, approximately $12 \mathrm{TBq}$ of radiocesium was modelled to be exported from the Abukuma basin in the first year after the accident representing on average $2 \%$ of the initial catchment inventory.

Kitamura et al. (2014) outlined an USLE-based model to estimate the ${ }^{137} \mathrm{Cs}$ discharge from 14 catchments that received fallout which are all outlined in Fig. 3. In particular, they focused on landuse as they argued it may have the greatest potential impact on soil erosion. This model is also described in Yamaguchi et al. (2014) and discussed in Kitamura et al. (2015). These authors reported that 8.4 TBq of ${ }^{137} \mathrm{Cs}$ will be exported to the Pacific Ocean in the immediate years following the FDNPP accident (Kitamura et al., 2014). This transfer of radiocesium to the Pacific Ocean can be compared to estimates of direct radiocesium discharge from the FDNPP between June 2011 and September 2012 (17 TBq), and a leakage event in August 2013 (24 TBq)(Kitamura et al., 2014; Yamaguchi et al., 2014). The model also estimates that only $35 \%$ of eroded soils are transported to the Pacific Ocean along with less than $1 \%$ of the initial radiocesium catchment inventory (Kitamura et al., 2014).

\subsection{Monitoring and modelling summary}

A convenient approach to examine radiocesium transfer results is to compare the percentage of initial radiocesium catchment inventory exported or remaining. At the plot or hillslope scale, Yoshimura et al. (2015a) determined that between 0.07 and $3.2 \%$ of the catchment ${ }^{137} \mathrm{Cs}$ inventory was exported with wash-off, with a mean annual export of $0.7 \%$ for their 7 USLE plots. For a forested experimental catchment, Shinomiya et al. (2014) reported that only $0.07 \%$ of the initial radiocesium inventory was exported during a typhoon event. In an outline of Fukushima related research projects, Saito and Onda (2015) indicated that less than $1 \%$ of the radiocesium inventory is transferred from hillslopes and discharged from catchments. 
This annual wash-off rate of less than $1 \%$ is similar to the catchment modelling results obtained at the subcatchment and catchment scales. In the Kuchibuto subcatchment of the Abukuma River, Kinouchi et al. (2015) reported that $0.8 \%$ of the initial fallout (or $0.28 \mathrm{TBq}$ ) was exported from the catchment. For the entire Abukuma catchment, Yamashiki et al. (2014) found that $1.1 \%$ of the radiocesium inventory was exported to the Pacific Ocean compared to an average of $2 \%$ reported by Pratama et al. (2015). In the upper Niida catchment, Ueda et al. (2013) reported that 0.3 to $0.5 \%$ of the initial catchment radiocesium fallout was exported. For all 14 coastal catchments, Kitamura et al. (2014) reported $99 \%$ of the catchment inventory remained with only $1 \%$ of the original fallout being exported. The highest ${ }^{137} \mathrm{Cs}$ export compared to catchment inventory of $<5 \%$ was modelled by Mori et al. (2014). Although there is a significant amount of radiocesium exported from hillslopes and catchments, this amount represents only a small fraction of the initial fallout inventory. Importantly, comparing research results through using the percentages of catchment inventories remaining and exported normalizes the results for comparison by removing the influences of catchment area, scale of research, or even the simply different approaches to quantifying catchment inventories.

Although they did not estimate discharge, Chartin et al. (2013) clearly demonstrated that the catchments that received fallout will become a perennial supply of radiocesium to the Pacific Ocean. This was confirmed by the modelling research reviewed above with significant volumes of radiocesium modelled to be exported annually from the fallout-affected catchments to the Pacific Ocean. In total, for the entire region, this amount was estimated to be 6.9-10 TBq by both samplebased (Yamashiki et al., 2014) and desktop modelling (Kitamura et al., 2014; Yamaguchi et al., 2014). Iwasaki et al. (2015) modelled that 3.3 TBq of the ${ }^{137}$ Cs export migrated through the lower reaches of the Abukuma River alone during Typhoon Roke. After the Abukuma River, (Kitamura et al., 2014) found that the Ukedo and Niida River catchments were the only catchments to export $>1$ TBq of ${ }^{137} \mathrm{Cs}$. Indeed, these coastal catchments will be significant long-term source of radiocesium to the Pacific Ocean. 
789 is particularly difficult. Several origins are possible: previous deposits associated with atmospheric bomb testing in the 1960s; direct releases from FDNPP to the ocean; and exports from coastal rivers of Eastern Japan. In order to quantify the respective contributions of these sources, the measurement of additional radionuclides in marine sediment may provide indications on their origin. For instance, a study showed that material exported by rivers draining the Fukushima radioactive pollution plume was characterised by a different ${ }^{239} \mathrm{Pu} /{ }^{241} \mathrm{Pu}$ atom ratio than the material originating from areas of Japan devoid of Fukushima fallout (Evrard et al., 2014b). Alternatively, the detection of the shorter-lived ${ }^{134} \mathrm{Cs}$ isotope in marine sediment indicates the presence of Fukushima fallout at this location, as ${ }^{134} \mathrm{Cs}$ fallout originating from the 1960 s atmospheric bomb fallout fully decayed (Bu et al., 2013).

\section{Management and research implications}

800

801

802

803

804

Characterizing the transfer of sediment and particle-borne radiocesium is required to predict future radiocesium dispersion in the Fukushima Prefecture and design and implement effective countermeasures. Reviewing the processes and dynamics governing radiocesium transfer from hillslopes to the Pacific Ocean provides not only a comprehensive depiction of the fundamental factors driving radiocesium transfer, it also highlights future potential radiocesium management challenges on one hand, and future research perspectives on the other.

In the fallout-affected areas, there has been a massive decontamination effort. Thousands of workers are decontaminating rice paddy fields, grasslands, and entire villages. For soil decontamination, the vegetation and litter are first removed followed by the removal of the topsoil. The impact of this decontamination on sediment modelling and radiocesium transfer research is unknown. The decontamination may temporarily increase the supply of radiocesium as the significant devegetation/soil management interventions is likely to result in an increase in the supply of sediments to riverine systems, as reported by Evrard et al. (2014a) and Lepage et al. (2014a) following 
preliminary decontamination works in the Upper Niida River catchment. The question is whether the

814 elevated suspended sediment loads mobilized by the decontamination will have elevated radiocesium quantities, be equivalent to pre-decontaminated levels, or be lowered through dilution with non-contaminated sediment? Further, will the decontamination efforts reduce the transfer of radiocesium from the hillslopes to the Pacific Ocean?

Examining the remaining catchment inventory from multiple studies provides a direct method to compare multi-scale research in the region. Although a significant quantity of radiocesium is exported from catchments to the Pacific Ocean, this amount represents only a small fraction of the initial catchment inventory $(<5 \%)$. Therefore, quantifying sediment (dis)connectivity is fundamental to not only understanding radiocesium migration in these catchments though also for highlighting potential areas that may accumulate and store radiocesium. The coastal plains, that remain inhabited, potentially serve as a large buffer zone which could temporarily store radiocesium transferred from the upstream forested, mountainous piedmont range. Floodplains and riparian zones that were not directly impacted by the FDNPP accident may receive significant pulses of radiocesium during flooding events that transfer contaminated sediment from upstream areas. Accordingly, it is important to determine whether and where are any important storages of radiocesium that need to be managed appropriately. The potential incorporation of Rouse number

830 threshold may help isolate locations of radiocesium deposition within the catchment to target 831 decontamination activities. After major typhoons, it may be necessary to analyse deposited material 832 in populated areas for radioactive contamination.

833 Perhaps the most critical potential sediment and radiocesium sink are rice paddy fields. Rice paddy 834 fields, depending on the time of year and hydrological environment, may be both sources and sinks 835 of radiocesium. The fertile soils of the Fukushima region make it important agriculturally. In 836 particular, paddy fields occupy approximately $70 \%$ of all farming area in the region (Wakahara et al., 837 2014). Unfortunately, radiocesium may transfer into rice. Contamination of agricultural products 
Table 5. Radiocesium transfer factor of different products collected after the FDNPP accident.

\begin{tabular}{llcc}
\hline Author(s) & Type & Number of samples & TF values \\
\hline Endo et al. (2013) & Root (rice) & 3 & $0.39 \pm 0.08$ \\
& Straw (rice) & 12 & $0.09 \pm 0.02$ \\
& Ear (rice) & 3 & $0.02 \pm 0.01$ \\
& Brown rice & 3 & $0.02 \pm 0.00$ \\
& Polished rice & 3 & $0.01 \pm 0.00$ \\
& Rice bran & 3 & $0.14 \pm 0.01$ \\
& Chaff (rice) & 1 & $0.05 \pm 0.01$ \\
Takeda et al. (2014) & Soybean grain & 46 & $0.09 \pm 0.11$ \\
Tazoe et al. (2012) & Mugwort & 6 & $0.02 \pm 0.01$ \\
& Clover & 1 & 0.03 \\
& Grass & 1 & 0.71 \\
\hline
\end{tabular}

Understanding the storage of radiocesium within dams and reservoirs is important. As the decontamination efforts remove significant inventories of radiocesium from low-to-medium impacted areas, dams and reservoirs may present significant long-term radiocesium storages. These reservoirs are not only major dams that provide water for the region, they also include hundreds of smaller irrigation and farm dams. These dams could store significant quantities of radiocesium that contaminating, for example, previously decontaminated paddies. 
Similarly, forests in the region will likely remain a significant long-term radiocesium reservoir.

858 Characterizing the storage and intra- and inter-forest radiocesium transfers will be necessary to 859 understand the transfer of radiocesium to and from forested hillslopes. This is important as forests received the bulk of medium to high radiocesium fallout. Further, most of the forested communities occur at high elevation on the coastal mountain ranges. Accordingly, they will likely act as a longterm source of dissolved and particulate (including sediment bound and organic matter bound) radiocesium. Forests may therefore contaminate downstream rice paddy fields, rural areas and rivers, again including potentially recently decontaminated landscapes. Importantly, it will be necessary to quantify radiocesium transfers from both deciduous and coniferous forests in order to accurately quantify radiocesium transfers from hillslopes to the Pacific Ocean.

In general, more research is needed to quantify radiocesium mobilization and transfer at the hillslope scale. In particular, a more detailed quantitative monitoring of soil erosion runoff under a variety of land uses is necessary to improve our understanding of the generation and transfer of sediment bound radiocesium at the hillslope scale, including the impact of different land uses (e.g. different

871 forests, rice paddy fields, rural residential and other cultivated landscapes). Direct monitoring of 872 hillslope erosion is necessary to ensure catchment scale models accurately reflect hillslope scale 873 erosion dynamics.

874 Along with a more accurate quantification of hillslope erosion dynamics, catchment scale models require a rigorous incorporation of the regional climate along with the important drivers and dynamics of radiocesium transfer from deposition zones. In particular incorporating the seasonality of flooding events to coincide with changes in vegetation in the forest and rice paddy landscapes may

878 improve the quantification of radiocesium transfer in the region. In the fallout-impacted catchments,

879 most radiocesium is transported in particulate form, mainly during floods generated by typhoons or, 880 to a lesser extent, by snowmelt. Further research into this seasonal cycle is important to understand 881 radiocesium dynamics in the Fukushima region. Indeed, it is necessary to fully comprehend the 
frequency and magnitude of heavy rainfall events in the past, in order to properly forecast potential rainfall driven radiocesium export in the future. Installing long-term riverine monitoring stations throughout the fallout impacted catchments to monitor flow and suspended sediment information while providing relationships to radiocesium would provide both a consistent long-term monitoring of radiocesium transfers. This long-term monitoring riverine data should be coupled with long-term monitoring of erosion from soils along with forestry radiocesium transfers to provide a concrete foundation for effective and accurate long-term modelling research through the provision of both reliable long-term calibration data and plot-scale transfer factors necessary to populate catchment scale models.

Ultimately, this type of holistic approach, incorporating the different fundamental components driving radiocesium transfer, is necessary. For example, research derived from monitoring at the local forest scale regarding the different transfer dynamics within different tree communities is needed in catchment modelling studies along with erosion data from the hillslope scale runoff research. Indeed a transdisciplinary approach, with a team including hydrologists, geomorphologists, soil and forest scientists, and mathematical modellers, will likely provide the best understanding of radiocesium transfer and migration in the fallout affected region. Through working together, a transdisciplinary team of researchers holds the greatest potential to accurately quantify the transfer of radiocesium from hillslopes to the Pacific Ocean. Indeed, such an approach will also greatly increase our understanding of sediment and material transfers in coastal mountainous environments subject to frequent typhoons.

\section{Conclusions}

The majority of radiocesium fallout from the FDNPP accident was deposited on forests covering $66 \%$ of the region exposed to the highest fallout levels. Although the majority of this fallout was transported to the soil with throughfall, litterfall may become a dominant pathway of contamination transfer in the future. In soils, most of the radiocesium remains in the upper $5 \mathrm{~cm}$ of the soil profile 
except in tilled fields where radiocesium is homogenized throughout the plough layer. Radiocesium is

908 strongly fixed to the finest mineral particles. Runoff generated from snowmelt and heavy rainfall

909 events generates and transfers sediments and their bound radiocesium. In fact, the major typhoons

910 in the region are known to transport the majority of radiocesium from hillslopes to the Pacific Ocean.

911 The FDNPP accident provides an important opportunity to research sediment transfers in general,

912 and radiocesium transfers in particular. Owing to the affinity of radiocesium to fine sediment

913 particles, there is an opportunity to use the accident to understand more about material transfers in

914 coastal mountainous regions subjected to massive typhoons. This understanding may be particularly

915 useful with the anticipated elevated rainfall intensities expected over the next century. Much can be

916 learnt from the Fukushima accident. The application of this learning is fundamental to manage the

917 fallout from this accident now, fallout from potential future accidents, and also simply increase our

918 understanding about the management of contaminants in rivers and riverine geomorphology in

919 general. 
921 We would like to thank the anonymous reviewers for their comments and feedback on the

922 manuscript. This work has been supported by the French National Research Agency (ANR) in the 923 framework of AMORAD project (ANR-11-RSNR-0002). 
Achim, P., Monfort, M., Le Petit, G., Gross, P., Douysset, G., Taffary, T., Blanchard, X., Moulin, C., part II. Pure and Applied Geophysics 171, 645-667.

Akai, J., Nomura, N., Matsushita, S., Kudo, H., Fukuhara, H., Matsuoka, S., Matsumoto, J., 2013. Mineralogical and geomicrobial examination of soil contamination by radioactive Cs due to 2011 Fukushima Daiichi Nuclear Power Plant accident. Physics and Chemistry of the Earth, Parts A/B/C 58, 57-67.

Akama, A., Kiyono, Y., Kanazashi, T., Shichi, K., 2013. Survey of radioactive contamination of sugi (Cryptomeria japonica D. Don) shoots and male flowers in Fukushima prefecture. Jpn. J. For. Environ 55, 105-111.

Bu, W., Zheng, J., Aono, T., Tagami, K., Uchida, S., Zhang, J., Honda, M., Guo, Q., Yamada, M., 2013. Vertical distributions of plutonium isotopes in marine sediment cores off the Fukushima coast after the Fukushima Dai-ichi Nuclear Power Plant accident. Biogeosciences 10, 2497-2511.

Chartin, C., Evrard, O., Onda, Y., Patin, J., Lefèvre, I., Ottlé, C., Ayrault, S., Lepage, H., Bonté, P., 2013. Tracking the early dispersion of contaminated sediment along rivers draining the Fukushima radioactive pollution plume. Anthropocene 1, 23-34.

Chino, M., Nakayama, H., Nagai, H., Terada, H., Katata, G., Yamazawa, H., 2011. Preliminary estimation of release amounts of ${ }^{131} \mathrm{I}$ and ${ }^{137} \mathrm{Cs}$ accidentally discharged from the Fukushima Daiichi nuclear power plant into the atmosphere. Journal of nuclear science and technology 48, 1129-1134. Endo, S., Kajimoto, T., Shizuma, K., 2013. Paddy-field contamination with ${ }^{134} \mathrm{Cs}$ and ${ }^{137} \mathrm{Cs}$ due to Fukushima Dai-ichi Nuclear Power Plant accident and soil-to-rice transfer coefficients. Journal of environmental radioactivity $116,59-64$.

Evrard, O., Chartin, C., Onda, Y., Lepage, H., Cerdan, O., Lefevre, I., Ayrault, S., 2014a. Renewed soil erosion and remobilisation of radioactive sediment in Fukushima coastal rivers after the 2013 typhoons. Sci. Rep. 4.

Evrard, O., Chartin, C., Onda, Y., Patin, J., Lepage, H., Lefèvre, I., Ayrault, S., Ottlé, C., Bonté, P., 2013. Evolution of radioactive dose rates in fresh sediment deposits along coastal rivers draining Fukushima contamination plume. Scientific reports 3.

Evrard, O., Pointurier, F., Onda, Y., Chartin, C., Hubert, A., Lepage, H., Pottin, A.-C., Lefèvre, I., Bonté, P., Laceby, J.P., Ayrault, S., 2014b. Novel Insights into Fukushima Nuclear Accident from Isotopic Evidence of Plutonium Spread along Coastal Rivers. Environ Sci Technol 48, 9334-9340.

Evrard, O., Van Beek, P., Gateuille, D., Pont, V., Lefèvre, I., Lansard, B., Bonté, P., 2012. Evidence of the radioactive fallout in France due to the Fukushima nuclear accident. Journal of environmental radioactivity $114,54-60$.

Fan, Q., Tanaka, K., Sakaguchi, A., Kondo, H., Watanabe, N., Takahashi, Y., 2014a. Factors controlling radiocesium distribution in river sediments: Field and laboratory studies after the Fukushima Dai-ichi Nuclear Power Plant accident. Applied Geochemistry 48, 93-103.

Fan, Q., Yamaguchi, N., Tanaka, M., Tsukada, H., Takahashi, Y., 2014b. Relationship between the adsorption species of cesium and radiocesium interception potential in soils and minerals: an EXAFS study. Journal of Environmental Radioactivity 138, 92-100.

Fujii, K., Ikeda, S., Akama, A., Komatsu, M., Takahashi, M., Kaneko, S., 2014. Vertical migration of radiocesium and clay mineral composition in five forest soils contaminated by the Fukushima nuclear accident. Soil Science and Plant Nutrition 60, 751-764.

Fujiwara, T., Saito, T., Muroya, Y., Sawahata, H., Yamashita, Y., Nagasaki, S., Okamoto, K., Takahashi, H., Uesaka, M., Katsumura, Y., 2012. Isotopic ratio and vertical distribution of radionuclides in soil affected by the accident of Fukushima Dai-ichi nuclear power plants. Journal of environmental radioactivity $113,37-44$.

Gonze, M.-A., Renaud, P., Korsakissok, I., Kato, H., Hinton, T.G., Mourlon, C., Simon-Cornu, M., 2014. Assessment of Dry and Wet Atmospheric Deposits of Radioactive Aerosols: Application to Fukushima Radiocaesium Fallout. Environ Sci Technol 48, 11268-11276. 
Govers, G., 1985. Selectivity and transport capacity of thin flows in relation to rill erosion. Catena 12 , 35-49.

Groëll, J., Quélo, D., Mathieu, A., 2014. Sensitivity analysis of the modelled deposition of ${ }^{137} \mathrm{Cs}$ on the Japanese land following the Fukushima accident. International Journal of Environment and Pollution 55, 67-75.

Hasegawa, M., Ito, M.T., Kaneko, S., Kiyono, Y., Ikeda, S., Makino, S.i., 2013. Radiocesium concentrations in epigeic earthworms at various distances from the Fukushima Nuclear Power Plant 6 months after the 2011 accident. Journal of environmental radioactivity 126, 8-13. Hashimoto, S., Ugawa, S., Nanko, K., Shichi, K., 2012. The total amounts of radioactively contaminated materials in forests in Fukushima, Japan. Scientific reports 2.

$\mathrm{He}, \mathrm{Q}$. , Walling, D.E., 1996. Interpreting particle size effects in the adsorption of ${ }^{137} \mathrm{Cs}$ and unsupported ${ }^{210} \mathrm{~Pb}$ by mineral soils and sediments. Journal of Environmental Radioactivity 30, 117137.

He, Q., Walling, D.E., 1997. The distribution of fallout ${ }^{137} \mathrm{Cs}$ and ${ }^{210} \mathrm{~Pb}$ in undisturbed and cultivated soils. Applied Radiation and Isotopes 48, 677-690.

Hilton, R.G., Galy, A., Hovius, N., Chen, M.-C., Horng, M.-J., Chen, H., 2008. Tropical-cyclone-driven erosion of the terrestrial biosphere from mountains. Nature Geosci 1, 759-762.

Iwagami, S., Tsujimura, M., Onda, Y., Nishino, M., Konuma, R., Abe, Y., Hada, M., Pun, I., Sakaguchi, A., Kondo, H., Yamamoto, M., Miyata, Y., Igarashi, Y., Submitted. Temporal changes in dissolved ${ }^{137} \mathrm{Cs}$ concentrations in groundwater and stream water in Fukushima after the Fukushima Dai-ichi Nuclear power Plant accident.

Iwasaki, T., Nabi, M., Shimizu, Y., Kimura, I., 2015. Computational modeling of ${ }^{137}$ Cs contaminant transfer associated with sediment transport in Abukuma River. Journal of Environmental Radioactivity 139, 416-426.

Jagercikova, M., Cornu, S., Le Bas, C., Evrard, O., 2015. Vertical distributions of ${ }^{137}$ Cs in soils: a metaanalysis. Journal of Soils and Sediments 15, 81-95.

Kakiuchi, H., Akata, N., Hasegawa, H., Ueda, S., Tokonami, S., Yamada, M., Hosoda, M., Sorimachi, A., Tazoe, H., Noda, K., 2012. Concentration of 3H in plants around Fukushima Dai-ichi Nuclear Power Station. Scientific reports 2.

Kanasashi, T., Sugiura, Y., Takenaka, C., Hijii, N., Umemura, M., 2015. Radiocesium distribution in sugi (Cryptomeria japonica) in Eastern Japan: translocation from needles to pollen. Journal of environmental radioactivity $139,398-406$.

Kato, H., Onda, Y., Gomi, T., 2012a. Interception of the Fukushima reactor accident-derived ${ }^{137} \mathrm{Cs}$, ${ }^{134} \mathrm{Cs}$ and ${ }^{131}$ I by coniferous forest canopies. Geophys Res Lett 39.

Kato, H., Onda, Y., Teramage, M., 2012b. Depth distribution of 137Cs, 134Cs, and 131l in soil profile after Fukushima Dai-ichi Nuclear Power Plant Accident. Journal of Environmental Radioactivity 111, 59-64.

Kawamura, H., Kobayashi, T., Furuno, A., In, T., Ishikawa, Y., Nakayama, T., Shima, S., Awaji, T., 2011. Preliminary numerical experiments on oceanic dispersion of ${ }^{131} \mathrm{I}$ and ${ }^{137} \mathrm{Cs}$ discharged into the ocean because of the Fukushima Daiichi nuclear power plant disaster. Journal of nuclear science and technology 48, 1349-1356.

Kikawada, Y., Hirose, M., Tsukamoto, A., Nakamachi, K., Oi, T., Honda, T., Takahashi, H., Hirose, K., 2014. Mobility of radioactive cesium in soil originated from the Fukushima Daiichi nuclear disaster: application of extraction experiments. J Radioanal Nucl Ch, 1-5.

Kinouchi, T., Yoshimura, K., Omata, T., 2015. Modeling radiocesium transport from a river catchment based on a physically-based distributed hydrological and sediment erosion model. Journal of Environmental Radioactivity 139, 407-415.

Kitamura, A., Kurikami, H., Yamaguchi, M., Oda, Y., Saito, T., Kato, T., Niizato, T., Iijima, K., Sato, H., Yui, M., 2015. Mathematical modeling of radioactive contaminants in the Fukushima environment. Nuclear Science and Engineering 179, 105-119.

Kitamura, A., Yamaguchi, M., Kurikami, H., Yui, M., Onishi, Y., 2014. Predicting sediment and cesium137 discharge from catchments in eastern Fukushima. Anthropocene 5, 22-31. 
Koarashi, J., Atarashi-Andoh, M., Matsunaga, T., Sato, T., Nagao, S., Nagai, H., 2012a. Factors affecting vertical distribution of Fukushima accident-derived radiocesium in soil under different landuse conditions. Science of the Total Environment 431, 392-401.

Koarashi, J., Moriya, K., Atarashi-Andoh, M., Matsunaga, T., Fujita, H., Nagaoka, M., 2012b. Retention of potentially mobile radiocesium in forest surface soils affected by the Fukushima nuclear accident. Scientific reports 2.

Kobayashi, T., Nagai, H., Chino, M., Kawamura, H., 2013. Source term estimation of atmospheric release due to the Fukushima Dai-ichi Nuclear Power Plant accident by atmospheric and oceanic dispersion simulations: Fukushima NPP Accident Related. Journal of Nuclear Science and Technology 50, 255-264.

Koizumi, A., Niisoe, T., Harada, K.H., Fujii, Y., Adachi, A., Hitomi, T., Ishikawa, H., 2013. ${ }^{137}$ Cs trapped by biomass within $20 \mathrm{~km}$ of the Fukushima Daiichi Nuclear Power Plant. Environ Sci Technol 47, 96129618.

Kozai, N., Ohnuki, T., Arisaka, M., Watanabe, M., Sakamoto, F., Yamasaki, S., Jiang, M., 2012. Chemical states of fallout radioactive $C s$ in the soils deposited at Fukushima Daiichi Nuclear Power Plant accident: Fukushima NPP Accident Related. Journal of nuclear science and technology 49, 473478.

Kurikami, H., Kitamura, A., Yamaguchi, M., Onishi, Y., 2013. Preliminary Calculation of Sediment and ${ }^{137}$ Cs Transport in the Ukedo River of Fukushima. Trans. Am. Nucl. Soc 109, 149-152. Kurikami, H., Kitamura, A., Yokuda, S.T., Onishi, Y., 2014. Sediment and ${ }^{137} \mathrm{Cs}$ behaviors in the Ogaki Dam Reservoir during a heavy rainfall event. Journal of Environmental Radioactivity 137, 10-17. Kuroda, K., Kagawa, A., Tonosaki, M., 2013. Radiocesium concentrations in the bark, sapwood and heartwood of three tree species collected at Fukushima forests half a year after the Fukushima Daiichi nuclear accident. Journal of environmental radioactivity 122, 37-42.

Le Petit, G., Douysset, G., Ducros, G., Gross, P., Achim, P., Monfort, M., Raymond, P., Pontillon, Y., Jutier, C., Blanchard, X., 2014. Analysis of radionuclide releases from the Fukushima Dai-Ichi nuclear power plant accident Part I. Pure and Applied Geophysics 171, 629-644.

Lepage, H., Evrard, O., Onda, Y., Chartin, C., Ayrault, S., Bonté, P., 2014a. Tracking the origin and dispersion of contaminated sediments transported by rivers draining the Fukushima radioactive contaminant plume Sediment Dynamics from the Summit to the Sea. IAHS Publ., New Orleans, Louisiana, USA.

Lepage, H., Evrard, O., Onda, Y., Lefèvre, I., Laceby, J.P., Ayrault, S., In Press. Depth distribution of cesium-137 in paddy fields across the Fukushima pollution plume in 2013. Journal of Environmental Radioactivity. Lepage, H., Evrard, O., Onda, Y., Patin, J., Chartin, C., Lefèvre, I., Bonté, P., Ayrault, S., 2014b. Environmental mobility of ${ }^{110 \mathrm{~m}} \mathrm{Ag}$ : lessons learnt from Fukushima accident (Japan) and potential use for tracking the dispersion of contamination within coastal catchments. Journal of environmental radioactivity $130,44-55$.

Loffredo, N., Onda, Y., Kawamori, A., Kato, H., 2014. Modeling of leachable ${ }^{137}$ Cs in throughfall and stemflow for Japanese forest canopies after Fukushima Daiichi Nuclear Power Plant accident. Science of the Total Environment 493, 701-707.

Long, N.Q., Truong, Y., Hien, P.D., Binh, N.T., Sieu, L., Giap, T., Phan, N., 2012. Atmospheric radionuclides from the Fukushima Dai-ichi nuclear reactor accident observed in Vietnam. Journal of environmental radioactivity $111,53-58$.

Malam Issa, O., Bissonnais, Y.L., Planchon, O., Favis-Mortlock, D., Silvera, N., Wainwright, J., 2006. Soil detachment and transport on field-and laboratory-scale interrill areas: erosion processes and the size-selectivity of eroded sediment. Earth surface processes and landforms 31, 929-939. Masson, O., Baeza, A., Bieringer, J., Brudecki, K., Bucci, S., Cappai, M., Carvalho, F., Connan, O., Cosma, C., Dalheimer, A., 2011. Tracking of airborne radionuclides from the damaged Fukushima Daiichi nuclear reactors by European networks. Environ Sci Technol 45, 7670-7677.

Matsuda, N., Mikami, S., Shimoura, S., Takahashi, J., Nakano, M., Shimada, K., Uno, K., Hagiwara, S., Saito, K., 2015. Depth profiles of radioactive cesium in soil using a scraper plate over a wide area 
surrounding the Fukushima Dai-ichi Nuclear Power Plant, Japan. Journal of environmental radioactivity $139,427-434$.

Matsunaga, T., Koarashi, J., Atarashi-Andoh, M., Nagao, S., Sato, T., Nagai, H., 2013. Comparison of the vertical distributions of Fukushima nuclear accident radiocesium in soil before and after the first rainy season, with physicochemical and mineralogical interpretations. Science of the Total Environment 447, 301-314.

Ministry of Education, C., Sports Science and Technology (MEXT), 2012. http://radioactivity.nsr.go.jp/ja/contents/7000/6289/24/203 0928.pdf (2012) (in Japanese). Minoura, K., Yamada, T., Hirano, S.-i., Sugihara, S., 2014. Movement of radiocaesium fallout released by the 2011 Fukushima nuclear accident. Nat Hazards 73, 1843-1862.

Mishra, S., Arae, H., Sorimachi, A., Hosoda, M., Tokonami, S., Ishikawa, T., Sahoo, S., 2015. Distribution and retention of Cs radioisotopes in soil affected by Fukushima nuclear plant accident. Journal of Soils and Sediments 15, 374-380.

Morgan, R., Quinton, J., Smith, R., Govers, G., Poesen, J., Auerswald, K., Chisci, G., Torri, D., Styczen, M., 1998. The European Soil Erosion Model (EUROSEM): a dynamic approach for predicting sediment transport from fields and small catchments. Earth surface processes and landforms 23, 527-544. Mori, K., Tada, K., Tawara, Y., Ohno, K., Asami, M., Kosaka, K., Tosaka, H., 2014. An Integrated Watershed Modeling to Assess the Long-term Fate of Fukushima-Derived Radionuclides, in: Ames, D.P., Quinn, N.W.T., Rizzoli, A.E. (Eds.), International Environmental Modelling and Software Society (iEMSs) 7th Intl. Congress on Env. Modelling and Software,, San Diego, CA, USA, .

Motha, J.A., Wallbrink, P.J., Hairsine, P.B., Grayson, R.B., 2002. Tracer properties of eroded sediment and source material. Hydrological Processes 16, 1983-2000.

Mouri, G., Golosov, V., Shiiba, M., Hori, T., 2014. Assessment of the caesium-137 flux adsorbed to suspended sediment in a reservoir in the contaminated Fukushima region in Japan. Environmental Pollution 187, 31-41.

Nagao, S., Kanamori, M., Ochiai, S., Inoue, M., Yamamoto, M., 2014. Migration behavior of ${ }^{134} \mathrm{Cs}$ and ${ }^{137}$ Cs in the Niida River water in Fukushima Prefecture, Japan during 2011-2012. J Radioanal Nucl Ch, $1-5$.

Nagao, S., Kanamori, M., Ochiai, S., Tomihara, S., Fukushi, K., Yamamoto, M., 2013. Export of ${ }^{134}$ Cs and ${ }^{137} \mathrm{Cs}$ in the Fukushima river systems at heavy rains by Typhoon Roke in September 2011. Biogeosciences Discuss. 10, 2767-2790.

Nakanishi, T., Matsunaga, T., Koarashi, J., Atarashi-Andoh, M., 2014. ${ }^{137}$ Cs vertical migration in a deciduous forest soil following the Fukushima Dai-ichi Nuclear Power Plant accident. Journal of environmental radioactivity 128, 9-14.

Nakao, A., Ogasawara, S., Sano, O., Ito, T., Yanai, J., 2014. Radiocesium sorption in relation to clay mineralogy of paddy soils in Fukushima, Japan. Science of the Total Environment 468, 523-529. Nearing, M., Foster, G., Lane, L., Finkner, S., 1989. A process-based soil erosion model for USDAWater Erosion Prediction Project technology. Trans. ASAE 32, 1587-1593.

Nemoto, K., Abe, J., 2013. Radiocesium absorption by rice in paddy field ecosystems, in: Nakanishi, T., Tanoi, K. (Eds.), Agricultural Implications of the Fukushima Nuclear Accident. Springer, pp. 19-27. Niimura, N., Kikuchi, K., Tuyen, N.D., Komatsuzaki, M., Motohashi, Y., 2015. Physical properties, structure, and shape of radioactive Cs from the Fukushima Daiichi Nuclear Power Plant accident derived from soil, bamboo and shiitake mushroom measurements. Journal of environmental radioactivity $139,234-239$.

Nishikiori, T., Watanabe, M., Koshikawa, M.K., Takamatsu, T., Ishii, Y., Ito, S., Takenaka, A., Watanabe, K., Hayashi, S., 2015. Uptake and translocation of radiocesium in cedar leaves following the Fukushima nuclear accident. Science of The Total Environment 502, 611-616.

Onishi, Y., Kurikami, H., Yokuda, S., 2014. Simulation of Sediment and Cesium Transport in the Ukedo River and the Ogi Dam Reservoir during a Rainfall Event using the TODAM Code. Pacific Northwest National Laboratory (PNNL), Richland, WA (US).

Phillips, J.M., Russell, M.A., Walling, D.E., 2000. Time-integrated sampling of fluvial suspended sediment: a simple methodology for small catchments. Hydrological Processes 14, 2589-2602. 
Pratama, M.A., Yoneda, M., Shimada, Y., Matsui, Y., Yamashiki, Y., 2015. Future projection of radiocesium flux to the ocean from the largest river impacted by Fukushima Daiichi Nuclear Power Plant. Scientific reports 5.

Renard, K.G., Foster, G.R., Weesies, G.A., Porter, J.P., 1991. RUSLE: Revised universal soil loss equation. Journal of soil and Water Conservation 46, 30-33.

Saito, K., Onda, Y., 2015. Outline of the national mapping projects implemented after the Fukushima accident. Journal of environmental radioactivity 139, 240-249.

Saito, K., Tanihata, I., Fujiwara, M., Saito, T., Shimoura, S., Otsuka, T., Onda, Y., Hoshi, M., Ikeuchi, Y., Takahashi, F., 2015. Detailed deposition density maps constructed by large-scale soil sampling for gamma-ray emitting radioactive nuclides from the Fukushima Dai-ichi Nuclear Power Plant accident. Journal of environmental radioactivity 139, 308-319.

Saito, T., Makino, H., Tanaka, S., 2014. Geochemical and grain-size distribution of radioactive and stable cesium in Fukushima soils: implications for their long-term behavior. Journal of environmental radioactivity $138,11-18$.

Sakaguchi, A., Tanaka, K., Iwatani, H., Chiga, H., Fan, Q., Onda, Y., Takahashi, Y., 2015. Size distribution studies of ${ }^{137} \mathrm{Cs}$ in river water in the Abukuma Riverine system following the Fukushima Dai-ichi Nuclear Power Plant accident. Journal of Environmental Radioactivity 139, 379-389.

Sakai, M., Gomi, T., Nunokawa, M., Wakahara, T., Onda, Y., 2014. Soil removal as a decontamination practice and radiocesium accumulation in tadpoles in rice paddies at Fukushima. Environmental Pollution 187, 112-115.

Sansone, U., Belli, M., Voitsekovitch, O.V., Kanivets, V.V., 1996. ${ }^{137} \mathrm{Cs}$ and ${ }^{90} \mathrm{Sr}$ in water and suspended particulate matter of the Dnieper River-Reservoirs System (Ukraine). Science of the Total Environment 186, 257-271.

Satou, Y., Sueki, K., Sasa, K., Kitagawa, J.-i., Ikarashi, S., Kinoshita, N., 2015. Vertical distribution and formation analysis of the ${ }^{131} \mathrm{I},{ }^{137} \mathrm{Cs},{ }^{129 \mathrm{~m}} \mathrm{Te}$, and ${ }^{110 \mathrm{~m}} \mathrm{Ag}$ from the Fukushima Dai-ichi Nuclear Power Plant in the beach soil. J Radioanal Nucl Ch 303, 1197-1200.

Sawhiney, B., 1972. Selective sorption and fixation of cations by clay minerals: a review. Clays Clay Miner 20, 93-100.

Schneider, S., Walther, C., Bister, S., Schauer, V., Christl, M., Synal, H.-A., Shozugawa, K., Steinhauser, G., 2013. Plutonium release from Fukushima Daiichi fosters the need for more detailed investigations. Scientific reports 3.

Schwantes, J.M., Orton, C.R., Clark, R.A., 2012. Analysis of a nuclear accident: Fission and activation product releases from the Fukushima Daiichi nuclear facility as remote indicators of source identification, extent of release, and state of damaged spent nuclear fuel. Environ Sci Technol 46, 8621-8627.

Shimizu, Y., 2003. Mutual relation between riverbed and bank variation characteristics in river channel landform formation. Annu. J. Hydraul. Eng 47, 643-648.

Shinomiya, Y., Tamai, K., Kobayashi, M., Ohnuki, Y., Shimizu, T., lida, S.i., Nobuhiro, T., Sawano, S., Tsuboyama, Y., Hiruta, T., 2014. Radioactive cesium discharge in stream water from a small watershed in forested headwaters during a typhoon flood event. Soil Science and Plant Nutrition 60, 765-771.

Shiozawa, S., 2013. Vertical migration of radiocesium fallout in soil in Fukushima, in: Nakanishi, T., Tanoi, K. (Eds.), Agricultural implications of the Fukushima nuclear accident. Springer, pp. 49-60. Shozugawa, K., Nogawa, N., Matsuo, M., 2012. Deposition of fission and activation products after the Fukushima Dai-ichi nuclear power plant accident. Environmental Pollution 163, 243-247. Steinhauser, G., 2014. Fukushima's Forgotten Radionuclides: A Review of the Understudied Radioactive Emissions. Environ Sci Technol 48, 4649-4663.

Tagami, K., Uchida, S., Uchihori, Y., Ishii, N., Kitamura, H., Shirakawa, Y., 2011. Specific activity and activity ratios of radionuclides in soil collected about $20 \mathrm{~km}$ from the Fukushima Daiichi Nuclear Power Plant: Radionuclide release to the south and southwest. Science of the Total Environment 409, 4885-4888. 
Takahashi, J., Tamura, K., Suda, T., Matsumura, R., Onda, Y., 2015. Vertical distribution and temporal changes of ${ }^{137} \mathrm{Cs}$ in soil profiles under various land uses after the Fukushima Dai-ichi Nuclear Power Plant accident. Journal of environmental radioactivity 139, 351-361.

Takeda, A., Tsukada, H., Yamaguchi, N., Takeuchi, M., Sato, M., Nakao, A., Hisamatsu, S.i., 2014.

Relationship between the radiocesium interception potential and the transfer of radiocesium from soil to soybean cultivated in 2011 in Fukushima Prefecture, Japan. Journal of environmental radioactivity $137,119-124$.

Tamura, T., 1964. Consequences of activity release: selective sorption reactions of cesium with soil Tanaka, K., Iwatani, H., Sakaguchi, A., Fan, Q., Takahashi, Y., 2015. Size-dependent distribution of radiocesium in riverbed sediments and its relevance to the migration of radiocesium in river systems after the Fukushima Daiichi Nuclear Power Plant accident. Journal of Environmental Radioactivity 139, 390-397.

Tanaka, K., Iwatani, H., Sakaguchi, A., Takahashi, Y., Onda, Y., 2013a. Local distribution of radioactivity in tree leaves contaminated by fallout of the radionuclides emitted from the Fukushima Daiichi Nuclear Power Plant. J Radioanal Nucl Ch 295, 2007-2014.

Tanaka, K., Iwatani, H., Sakaguchi, A., Takahashi, Y., Onda, Y., 2014. Relationship between particle size and radiocesium in fluvial suspended sediment related to the Fukushima Daiichi Nuclear Power Plant accident. J Radioanal Nucl Ch, 1-7.

Tanaka, K., Iwatani, H., Takahashi, Y., Sakaguchi, A., Yoshimura, K., Onda, Y., 2013b. Investigation of Spatial Distribution of Radiocesium in a Paddy Field as a Potential Sink. PLoS ONE 8.

Tanaka, K., Sakaguchi, A., Kanai, Y., Tsuruta, H., Shinohara, A., Takahashi, Y., 2013c. Heterogeneous distribution of radiocesium in aerosols, soil and particulate matters emitted by the Fukushima Daiichi Nuclear Power Plant accident: retention of micro-scale heterogeneity during the migration of radiocesium from the air into ground and river systems. J Radioanal Nucl Ch 295, 1927-1937. Tazoe, H., Hosoda, M., Sorimachi, A., Nakata, A., Yoshida, M., Tokonami, S., Yamada, M., 2012. Radioactive pollution from Fukushima Daiichi Nuclear Power Plant in the terrestrial environment. Radiation protection dosimetry 152, 198-203.

Teramage, M.T., Onda, Y., Kato, H., Gomi, T., 2014a. The role of litterfall in transferring Fukushimaderived radiocesium to a coniferous forest floor. Science of the Total Environment 490, 435-439. Teramage, M.T., Onda, Y., Patin, J., Kato, H., Gomi, T., Nam, S., 2014b. Vertical distribution of radiocesium in coniferous forest soil after the Fukushima nuclear power plant accident. Journal of environmental radioactivity $137,37-45$.

Thakur, P., Ballard, S., Nelson, R., 2013. An overview of Fukushima radionuclides measured in the northern hemisphere. Science of The Total Environment 458-460, 577-613.

Torri, D., Sfalanga, M., Del Sette, M., 1987. Splash detachment: runoff depth and soil cohesion. Catena 14, 149-155.

Tsuji, H., Yasutaka, T., Kawabe, Y., Onishi, T., Komai, T., 2014. Distribution of dissolved and particulate radiocesium concentrations along rivers and the relations between radiocesium concentration and deposition after the nuclear power plant accident in Fukushima. Water research 60, 15-27.

Ueda, S., Hasegawa, H., Kakiuchi, H., Akata, N., Ohtsuka, Y., Hisamatsu, S.i., 2013. Fluvial discharges of radiocaesium from watersheds contaminated by the Fukushima Dai-ichi Nuclear Power Plant accident, Japan. Journal of Environmental Radioactivity 118, 96-104.

UNSCEAR, 2000. Sources and effects of ionizing radiation: sources. United Nations Scientific Committee on the Effects of Atomic Radiation (UNSCEAR). United Nations Publications, New York. Van Oost, K., Verstraeten, G., Doetterl, S., Notebaert, B., Wiaux, F., Broothaerts, N., Six, J., 2012. Legacy of human-induced C erosion and burial on soil-atmosphere $C$ exchange. Proceedings of the National Academy of Sciences 109, 19492-19497.

Vandaele, K., Poesen, J., Govers, G., van Wesemael, B., 1996. Geomorphic threshold conditions for ephemeral gully incision. Geomorphology 16, 161-173. 
Wakahara, T., Onda, Y., Kato, H., Sakaguchi, A., Yoshimura, K., 2014. Radiocesium discharge from paddy fields with different initial scrapings for decontamination after the Fukushima Dai-ichi Nuclear Power Plant accident. Environmental Science: Processes \& Impacts 16, 2580-2591.

Wauters, J., Elsen, A., Cremers, A., Konoplev, A., Bulgakov, A., Comans, R., 1996. Prediction of solid/liquid distribution coefficients of radiocaesium in soils and sediments. Part one: a simplified procedure for the solid phase characterisation. Applied Geochemistry 11, 589-594.

Wetherbee, G.A., Gay, D.A., Debey, T.M., Lehmann, C.M., Nilles, M.A., 2012. Wet deposition of fission-product isotopes to North America from the Fukushima Dai-ichi Incident, March 2011. Environ Sci Technol 46, 2574-2582.

Wischmeier, W.H., Smith, D.D., 1958. Rainfall energy and its relationship to soil loss. Transactions American Geophysical Union 39, 285-291.

Yamada, S., Kitamura, A., Kurikami, H., Yamaguchi, M., Malins, A., Machida, M., 2015. Sediment and ${ }^{137} \mathrm{Cs}$ transport and accumulation in the Ogaki Dam of eastern Fukushima. Environmental Research Letters 10, 014013.

Yamaguchi, M., Kitamura, A., Oda, Y., Onishi, Y., 2014. Predicting the long-term ${ }^{137}$ Cs distribution in Fukushima after the Fukushima Dai-ichi nuclear power plant accident: a parameter sensitivity analysis. Journal of Environmental Radioactivity 135, 135-146.

Yamaguchi, N., Eguchi, S., Fujiwara, H., Hayashi, K., Tsukada, H., 2012. Radiocesium and radioiodine in soil particles agitated by agricultural practices: Field observation after the Fukushima nuclear accident. Science of The Total Environment 425, 128-134.

Yamashiki, Y., Onda, Y., Smith, H.G., Blake, W.H., Wakahara, T., Igarashi, Y., Matsuura, Y., Yoshimura, K., 2014. Initial flux of sediment-associated radiocesium to the ocean from the largest river impacted by Fukushima Daiichi Nuclear Power Plant. Scientific Reports 4.

Yoshida, N., Kanda, J., 2012. Tracking the Fukushima radionuclides. Science 336, 1115-1116.

Yoshida, N., Takahashi, Y., 2012. Land-surface contamination by radionuclides from the Fukushima Daiichi Nuclear Power Plant accident. Elements 8, 201-206.

Yoshihara, T., Hashida, S.-n., Abe, K., Ajito, H., 2014a. A time dependent behavior of radiocesium from the Fukushima-fallout in litterfalls of Japanese flowering cherry trees. Journal of environmental radioactivity $127,34-39$.

Yoshihara, T., Matsumura, H., Hashida, S.-n., Nagaoka, T., 2013. Radiocesium contaminations of 20 wood species and the corresponding gamma-ray dose rates around the canopies at 5 months after the Fukushima nuclear power plant accident. Journal of environmental radioactivity 115, 60-68. Yoshihara, T., Matsumura, H., Tsuzaki, M., Wakamatsu, T., Kobayashi, T., Hashida, S.-n., Nagaoka, T., Goto, F., 2014b. Changes in radiocesium contamination from Fukushima in foliar parts of 10 common tree species in Japan between 2011 and 2013. Journal of environmental radioactivity 138, 220-226. Yoshikawa, N., Obara, H., Ogasa, M., Miyazu, S., Harada, N., Nonaka, M., $2014 .{ }^{137}$ Cs in irrigation water and its effect on paddy fields in Japan after the Fukushima nuclear accident. Science of The Total Environment 481, 252-259.

Yoshimura, K., Onda, Y., Kato, H., 2015a. Evaluation of radiocaesium wash-off by soil erosion from various land uses using USLE plots. Journal of Environmental Radioactivity 139, 362-369.

Yoshimura, K., Onda, Y., Sakaguchi, A., Yamamoto, M., Matsuura, Y., 2015b. An extensive study of the concentrations of particulate/dissolved radiocaesium derived from the Fukushima Dai-ichi Nuclear Power Plant accident in various river systems and their relationship with catchment inventory. Journal of Environmental Radioactivity 139, 370-378. 